\title{
Aliphatic Extractive Effects on Acetic Acid Catalysis of Typical Agricultural Residues to Xylo- Oligosaccharide and Enzymatic Hydrolysability of Cellulose
}

\author{
Jianming Guo \\ Nanjing Forestry University \\ Kaixuan Huang \\ Nanjing Forestry University \\ Rou Cao \\ Nanjing Forestry University \\ Junhua Zhang \\ Northwest Agriculture and Forestry University \\ Yong Xu ( $D$ 1030731413@qq.com ) \\ Nanjing Forestry University https://orcid.org/0000-0002-8106-326X
}

\section{Research Article}

Keywords: Aliphatic extractives, Acetic acid acidolysis, Xylo-oligosaccharides, Enzymatic hydrolysis, Agricultural residues

Posted Date: March 23rd, 2021

DOI: https://doi.org/10.21203/rs.3.rs-333308/v1

License: (c) (1) This work is licensed under a Creative Commons Attribution 4.0 International License.

Read Full License

Version of Record: A version of this preprint was published at Biotechnology for Biofuels on April 17th, 2021. See the published version at https://doi.org/10.1186/s13068-021-01952-8. 
1 Aliphatic extractive effects on acetic acid catalysis of typical agricultural residues

2 to xylo-oligosaccharide and enzymatic hydrolysability of cellulose

3

4

$5 \mathbf{b}, \mathbf{c}$ *

6

$7 \quad{ }^{a}$ Key Laboratory of Forestry Genetics \& Biotechnology (Nanjing Forestry University),

$8 \quad$ Ministry of Education, Nanjing 210037, People's Republic of China

$9{ }^{b}$ Jiangsu Co-Innovation Center of Efficient Processing and Utilization of Forest

* Corresponding author at: College of Chemical Engineering, Nanjing Forestry University. No. 159 Longpan Road, Nanjing 210037. People's Republic of China.

\section{E-mail address: xuyong@njfu.edu.cn (Y.X.)}

Tel: +8602585427587

Fax: +8602585427587 


\section{Abstract}

Background: Xylo-oligosaccharide is the spotlight of functional sugar that improves economic benefits of lignocellulose biorefinery. Acetic acid acidolysis technology provides a promising application for xylo-oligosaccharide commercial production, but it is restricted by the aliphatic (wax-like) compounds, which cover the outer and inner surfaces of plants.

Results: We removed aliphatic compounds by extraction with two organic solvents. The benzene-ethanol extraction increased the yield of acidolyzed xylo-oligosaccharides of corncob, sugarcane bagasse, wheat straw, and poplar sawdust by $14.79 \%, 21.05 \%$, $16.68 \%$, and $7.26 \%$ while ethanol extraction increased it by $11.88 \%, 17.43 \%, 1.26 \%$, and $13.64 \%$, respectively.

Conclusion: The single ethanol extraction was safer, more environmentally-friendly and more cost-effective than benzene-ethanol solvent. In short, organic solvents extraction provided a promising auxiliary method for the selective acidolysis of herbaceous xylan to xylo-oligosaccharides, while it had minimal impact on woody poplar.

Keywords: Aliphatic extractives; Acetic acid acidolysis; Xylo-oligosaccharides; Enzymatic hydrolysis; Agricultural residues 


\section{Background}

Agricultural residues and forestry wood residues are some of the most abundant renewable resources in the world and can be obtained on a large scale at a low cost. The use of carbohydrates, which are present in agricultural residues, to produce biofuels and chemicals is both energy-efficient and environment-friendly [1]. Lignocellulosic materials such as agricultural wastes are composed of $40-50 \%$ cellulose, $25-30 \%$ hemicellulose, and 15-20\% lignin along with other extractable components [2]. Among these constituents, cellulose and hemicellulose are macromolecules composed of different monosaccharides, mainly glucan and xylan, respectively, and are the main sugar platforms for biorefinery of agricultural residues. In agricultural residues, cellulose, hemicellulose, and lignin are bound through both covalent cross-linking and non-covalent forces. Lignin and hemicellulose wrap themselves around cellulose to form a watertight structure, resulting in a small accessible surface area, which makes the bioconversion of agricultural residues difficult [3].

Pretreatment of agricultural residues can break its natural structure either by dissolving or separating cellulose, hemicellulose, and lignin, thereby increasing its digestibility, resulting in effective bioconversion of cellulose and hemicellulose [4,5]. In the past, several economic and effective pretreatment techniques have been used for lignocellulosic biorefining, resulting in oligosaccharides and monosaccharides. Up to now, the most concerned agricultural residues pretreatment techniques include steam explosion, dilute acid pretreatment, alkali pretreatment, ionic liquid pretreatment, and inorganic salt pretreatment [6,7]. It is well known that pretreatment under mild 
conditions can selectively depolymerize the xylan skeleton in hemicellulose, producing xylo-oligosaccharides (XOS) as the main degradation product $[8,9]$. Meanwhile, the removal of extractives and side reactions leading to monosaccharide degradation and lignin depolymerization will also occur in the reaction medium [10]. Our previous work found that the pretreatment of corncob (CC) [11], viscose fiber [12], and poplar [13] with green, mild, and recyclable acetic acid, resulted in effective depolymerization of hemicellulose and produced several xylan derivatives with high added value, such as XOS, xylose, and furfural. Thus, the combined conversion of hemicellulose and cellulose was performed through pretreatment with acetic acid combined with cellulase hydrolysis technology. Currently, this is a highly effective technique to achieve lignocellulosic biorefining.

XOS contains approximately 2-10 xylose units along with $\beta-1,4$-glycosidic bonds. It is also identified as emerging prebiotic products for human and animal use, feeding on stimulated intestinal bacteria, such as Bifidobacterium, lactobacillus, etc. [14,15]. XOS is a novel and functional ingredient that finds use in the fields of medicine, health care, and as a feed additive, and has a market price of approximately $\$ 22-50 / \mathrm{kg}$ [16]. The conversion of hemicellulose xylan to XOS products is cost-effective that is critical for the commercialization of lignocellulosic biorefining. Therefore, there is extensive ongoing research on the synthesis of XOS. Acetic acid pretreatment is a green and economical hemicellulose degradation method [11,17]. Zhang et al. obtained the highest XOS yield of $45.91 \%$ by pretreating $\mathrm{CC}$ with acetic acid, while achieving a cellulose conversion rate of more than $91 \%$, thus achieving the efficient conversion of 
hemicellulose and cellulose [11]. Interestingly, the pretreatment of wheat straw (WS) with acetic acid resulted in the XOS yield of 38.21\% [18]. This discrepancy in yield might be attributed to a variety of reasons, including the low xylan content, high lignin content, and recalcitrant structure of wood capillary. These factors combine and enhance the differences of XOS preparations, eg. the xylan content of WS (20-25\%) was generally lower than that of CC (35\%) [19,20], while the lignin content was $21 \%$ and $13 \%$ in WS and CC respectively. Accordingly, we obtained $54.16 \%$ and $39.19 \%$ XOS yield from the above two materials $[21,22]$. The surface of WS was covered with a protective layer of wax [23], which could have resulted in an inconsistent erosion and penetration of acetic acid to WS compared with CC. The wax mentioned here refers to the cuticle on the plant surface, which is an epidermal lipid component covered on the outer epidermis of the aerial part of the plant. This cuticular wax regulates the moisture content inside the plant and prevents the infiltration of exogenous factors into the plant, thus acting as the structural stabilizing component of the primary epidermal tissue of the plant [24-26]. Many studies have shown that the removal of plant cuticular wax performed some positive impacts on agricultural residues biorefinery. For example, Kádár et al. removed the cuticle and epidermis wax of WS through plasma-assisted pretreatment to increase the ethanol yield of WS from $21 \%$ to $67 \%$ [27]; Gao et al. dewaxed bagasse with the mixture of petroleum ether and ethanol also effectively improved the digestibility of cellulose and xylan of bagasse [28]. Therefore, dewaxing is a promising candidate technique to improve the yield of acidolyzed XOS from agricultural residues. The components of plant cuticle wax were mostly complex 
mixtures of long-chain aliphatic and a few were cyclic components [29,30], and dewaxing methods includes organic solvents extraction [24], supercritical carbon dioxide extraction [29,31], alkali washing [32] and enzyme treatment [33], etc., wherein organic solvent extraction is the most popular technique for the industrial plant dewaxing. Generally, volatile polar or nonpolar organic solvents, such as methanol, ethanol, hexane, benzene, chloroform, petroleum ether and so on, are used for wax extraction. Benzene and ethanol are common extraction reagents. Therefore, in this study, benzene-ethanol mixed solvent and a single ethanol solvent were used to extract and compare agricultural residues, to obtain a more environmentally friendly and efficient wax removal method.

Here, four typical agricultural residues: CC, sugarcane bagasse (SB), WS, and poplar sawdust (PS) were subjected to benzene-ethanol extraction (BEE) and ethanol extraction (EE) (preliminary dewaxing treatment), respectively to verify the effect of removing the extractives on agricultural residues conversion, wherein poplar was set as a contrast sample opposite to grass agricultural residues. Next, we analyzed and compared the extracted components and explored the effects of preliminary dewaxing treatment on the yield of XOS after acetic acid catalysis and the enzymatic hydrolyzability of cellulose. Thus, this work proposed a composite pretreatment program that could effectively promote the high-value utilization of agricultural residues.

\section{Results and discussion}

\section{Comparison of aliphatic extractives from various agricultural residues}


BEE was $1.60 \%, 1.55 \%, 2.07 \%$, and $1.22 \%$, respectively while from EE was $4.28 \%$, was significantly higher than that of BEE. Among these four agricultural residues, the extraction yield of the total solids from $\mathrm{CC}, \mathrm{SB}$, and WS was markedly higher than that of woody PS, which was attributed to the fact that poplar logs have been peeled and processed compared with the intact herbages.

Based on NREL method's composition analysis, we found that only glucose- and xylose-based compounds were present in various extractives, which accounted for approximately $3 \%$ of the total extractive mass. These extractable carbohydrates involved mainly oligosaccharides and trace amounts of monosaccharides, which were precursors of starch and cellulose. Unlike CC, SB, and WS, we found more glucosebased compounds than xylose-based compounds in the benzene-ethanol extractives and the ethanol extractives of PS. We speculated that was attributed to the presence of flavonoids in PS [34,35], which could easily combine with sugar to form glycosides. After NREL acidolysis, glycosides generated glucose-like structures. Both BEE and EE were considered reasonable methods for the extraction of mainly aliphatic compounds other than detectable carbohydrate compounds from agricultural residues. The aliphatic extractives of woody poplar were obviously less than that of herbaceous materials. The ethanol-water solution extracted approximately 2-3 times more substrate than the benzene-ethanol solution since the former solution had higher polarity than the latter, which benefited the solubility of small and polar carbohydrates. On the contrary, 
benzene enhanced the non-polar nature of the extraction solvent that repelled polar sugars and compounds.

The composition of the non-derivatized solvent extractives was identified by GCMS. Table 2 lists the fingerprints of the benzene-ethanol extractives and ethanol extractives of all four agricultural residues. The cuticular wax of plants mainly contains long-chain aliphatic compounds, derived from long-chain fatty acids, along with terpenes, flavonoids, sterols, etc. [36]. Aliphatic compounds were also the main extractives in BEE and EE from CC, SB, WS, and PS. From benzene-ethanol extractives and ethanol extractives of $\mathrm{CC}$, we obtained cis-vaccenic acid and 2palmitoylglycerol as the most abundant components, respectively. However, benzeneethanol extractives of SB, WS, and PS revealed n-hexadecanoic acid as the most abundant component. The proportions of various compounds in the ethanol extractives of SB, WS, and PS were equivalent and contained a complex array of aliphatic compounds. Among these complex extractives of the four agricultural residues, nhexadecanoic acid appeared as a common component, abundantly present in both the benzene-ethanol extractives and ethanol extractives, consistent with previous reports [36,37]. Among the other components, $n$-hexadecanoic acid was a saturated fatty acid, cis-vaccenic acid was an unsaturated fatty acid, and 2-palmitoylglycerol was a fatty acid ester. These long-chain fatty acids are synthesized in the epidermis of plants and used for the formation of cuticular wax [36]. Cutin is a covalently cross-linked polymer that forms a dense electron layer on the epidermal cells, restraining plant growth and effectively resisting the attack of foreign impurities $[38,39]$. 

and alkanes, the composition of the solvent extractives of PS from hardwood was not as rich as the solvent extractives of the other three herbaceous plants. In general, plant

epidermal waxes consisted mainly composed of a mixture of aliphatic hydrocarbons and their derivatives with a carbon chain length between 20 and 40 [26]. The content and composition of aliphatic extractives of agricultural residues from different sources are also different due to their different contents of wax, fat, pigment, and other substances. From Table 1, we found that the content of poplar extractives is less than the other three gramineous materials, which is related to the characteristics of the wood itself, and the extractives of wood are relatively less. Besides, it was confirmed by GCMS analysis (Table 2) that the types of chemical components in benzene-ethanol extractives and ethanol extractives of CC, SB, WS and PS were generally consistent. It mainly includes fatty acids, fatty alcohols, alkanes, aldehydes, ketones, steroid ketones, sterols, phenols, esters, triglycerides, monoglycerides, aromatic hydrocarbon, etc. However, it can be seen from Table 3 that the component types of the extractives were related to the types of extractants. The benzene-ethanol extractives were mainly fatty acids, while the ethanol extractives were mostly long-chain alkanes. Moreover, the components of ethanol extractives were more abundant than those of benzene-ethanol extractives, which was consistent with previous reports. We speculate that this was due to the greater polarity of ethanol, which could extract more polar compounds [40]. In summary, the composition of benzene-ethanol extractives was relatively simple, mainly fatty acids, along with a small number of aldehydes, ketones, esters, 
monoglycerides, and triglycerides. On the contrary, ethanol extractives were complex in composition, was rich in alkanes compared with fatty acids, and also included aldehydes, ketones, steroid ketones, sterols, esters, etc. Overall, both BEE and EE confirmed the diversity of plant cuticle wax, which were deposited on the plant surface and tissue interior to protect the plant from biotic or abiotic stress [41]. In other words, these aliphatic extractives were possible obstacles to lignocellulosic biorefining.

\section{Effects of extraction on the XOS yield of agricultural residues}

We studied the conversion of xylan from agricultural residues to verify the effect of organic solvent extraction on the biorefinery of agricultural residues. Next, CC, SB, WS, and PS underwent the same treatment to further evaluate the universal applications of organic solvent extraction and to compare the differences of different agricultural residues affected by their respective extractives. Fig. 1a-d show the results of the degradation of xylan in unextracted agricultural residues to XOS. After acetic acid catalysis, the XOS yield of CC, SB, WS, and PS was $37.11 \%, 45.12 \%, 36.92 \%$, and $23.16 \%$, respectively. The main XOS obtained from the four agricultural residues were xylobiose, xylotriose, and xylotetraose, while xylopentose and xylohexose accounted were the minor components. Next, four types of agricultural residues after BEE and EE were also catalyzed using acetic acid under the same reaction conditions. Fig. 1a-d show the yields and components of the obtained XOS. All four agricultural residues showed an improved yield of XOS, after BEE or EE. Compared with the XOS yield obtained from raw materials without extraction catalyzed by acetic acid, the relative increase of XOS of CC, SB, WS, and PS after BEE catalyzed by acetic acid were $14.79 \%, 21.05 \%$, 
$16.68 \%$, and $7.26 \%$, respectively. Similarly, after EE, the relative increase of XOS from acetic acid catalyzed CC, SB, WS, and PS were $11.88 \%, 17.43 \%, 1.26 \%$, and $13.64 \%$, respectively. For WS, the wax content was obviously the most. Since the components of plant cuticle wax were mainly non-polar components, we believe that the non-polar solvent benzene has a better wax solubility than ethanol, so BEE was more suitable than EE to improve the degradation ability of WS to acetic acid. Furthermore, in each dataset, the increase in the yield of XOS was also reflected in the content of xylobiose, xylotriose, and xylotetraose, amongst which xylobiose showed the highest increase, while the change in xylopentose and xylohexose was insignificant.

Thus, the extraction of agricultural residues with organic solvents had a selective and positive effect on the yield of XOS from agricultural residues catalyzed by acetic acid. Generally, SB showed the highest XOS yield among all four agricultural residues, which was due to the fact that SB was mechanically squeezed before collection, which made it very soft and absorbent, and also removed some water extractives, while CC and WS were directly used for pretreatment after air drying, and PS showed very inert xylan conversion since it is derived from hardwood. Both BEE and EE could effectively extract cuticular wax components (aliphatic compounds) from all four agricultural residues. The role of physical and chemical properties of plant cuticular wax in protecting plants, reducing the deposition of dust, pollen, and air pollutants on the surface of plants, in preventing bacterial or fungal invasion is well known [36]. Thus, we assumed that the cuticular plant wax had a similar defense against acetic acid. When BEE or EE was not performed, the cuticular wax resisted the protons of acetic acid in 
all four agricultural residues and thus may have affected the diffusion of products such as XOS as well as restricted the movement of bacteria or fungi. However, the use of benzene-ethanol or ethanol resulted in partial removal of the cuticle wax components in the agricultural residues. Therefore, the protons of acetic acid were easier to attack the agricultural residues in this case, which accelerated the degradation of xylan and improved the yield of XOS.

The extractives from agricultural residues were extremely complex components.

The benzene-ethanol extractives and ethanol extractives were re-added to the corresponding extracted agricultural residues, and the mixture was subjected to catalysis with acetic acid under the previous reaction conditions to study the influence mechanism of BEE and $\mathrm{EE}$ in the preparation of XOS from the four agricultural residues catalyzed by acetic acid. Fig. 1a-d show that after the re-addition of benzeneethanol extractives followed by acetic acid catalysis, the XOS yields of CC, SB, WS, and PS were $45.70 \%, 58.83 \%, 50.92 \%$, and $26.14 \%$, respectively. Compared with acetic acid catalyzed raw materials, the relative increase of XOS of CC, SB, WS, and PS after the re-addition of benzene-ethanol extractives were $23.13 \%, 30.39 \%, 37.91 \%$, and $12.89 \%$, respectively. Similarly, after the re-addition of ethanol extractives followed by acetic acid catalysis, the XOS yields of CC, SB, WS, and PS were also significantly increased. The yields of XOS in CC, SB, WS, and PS were harvested at $44.42 \%, 58.5 \%, 42.04 \%$, and $26.37 \%$, respectively. Compared with the XOS yields obtained from the raw materials, the relative increase of XOS of CC, SB, WS and PS after the re-addition of ethanol extractives were $19.68 \%, 29.66 \%, 13.85 \%$ and $13.88 \%$. 
The results of GC-MS analysis showed that there were more non-polar alkanes in PS extractives. Whether natural or re-added, these components will lead to the reduction of hydrogen proton solubility and transmission capacity of acetic acid dissociation. Therefore, PS have always been the stuff with the worst catalytic performance for acetic acid, while three herbaceous plants have shown superior catalytic performance of acetic acid.

Thus, the re-addition of benzene-ethanol extractives or ethanol extractives to the extracted agricultural residues promoted the degradation of xylan into XOS. The components of the extractives not only contained aliphatic compounds, such as fatty acids, aldehydes, and alkanes but also included some oligosaccharide substances, based on the results of NREL-HPLC analysis, as listed in Table 1. Therefore, the effective conversion of saccharides contained in the extractives during the acetic acid catalysis process may be one of the reasons for increasing the yield of XOS, and there may be substances with equivalent acid catalysis effect in the extractive, which may be the main reason for the improvement of XOS yield.

\section{Extraction Effect on xylan degraded by-product}

During the acetic acid catalysis of agricultural residues, excessive degradation of pentose produces furfural and acetic acid [42], and acid-catalyzed dehydration of hexose leads to the formation of hydroxymethyl furfural [43]. These substances, which are the by-products of lignocellulosic biorefining, affect the industrial value of the main products. However, they also have important roles, such as furfural and hydroxymethyl furfural are precursors of synthetic commercial chemicals and liquid fuels [44]. Here, 
we investigated the degradation mechanism of xylose, furfural, and hydroxymethyl furfural, which were by-products produced in the process of preparing XOS from four agricultural residues. As shown in Fig. 2a-d, before and after organic solvent extraction, CC, SB, WS, and PS were catalyzed by acetic acid to obtain xylose, furfural, and hydroxymethyl furfural as by-products, along with high value-added XOS. Their degradation pattern was consistent with the variation in the yield of XOS. Before and after extraction, the yield of xylose from CC, SB, WS, and PS catalyzed by acetic acid was in the range of $15.05 \%-23.13 \%, 27.61 \%-32.36 \%, 20.85 \%-29.97 \%$, and $10.64 \%$ $11.77 \%$, respectively. When four agriculture residues, including corncob, sugar bagasse, wheat straw, and poplar sawdust, were pretreated with acetic acid, the yield of XOS obtained from poplar was the lowest. The main reason might be due to the inerter chemical structure, lower xylan content and higher lignin content in woody materials that agricultural residues [22]. The xylose and XOS produced from the four agricultural residues catalyzed by acetic acid before and after BEE or EE maintained a reasonably constant proportion, and the content was within the normal range. In several groups of experiments, the content changes in furfural and hydroxymethyl furfural were insignificant. In other words, CC, SB, WS and PS were subjected to BEE and EE respectively, and then catalyzed with acetic acid, which improved their XOS yields, but a large number of by-products such as furfural and hydroxymethyl furfural were not accumulated under these conditions. Therefore, this confirmed that BEE and EE increased the accessibility of agricultural residues and their acidolysis selectivity. Among the four agricultural residues, $\mathrm{CC}, \mathrm{SB}$, and WS, from gramineous plants, 
showed better acidolysis and extraction applicability compared with PS, which is derived from woody plants. Fig.1d shows that the yield of XOS from acetic acid catalysis of PS also improved after extraction. However, the hardwood characteristics of PS caused an inertness to degradation of poplar xylan, which put PS at a disadvantage in the preparation process of XOS.

The total yield of the XOS + Xylose + Furfural (XXF) was used as an evaluation index in order to more intuitively show the effect of extraction on the degradation and dissolution of xylan components of these agricultural residues, which also summarized the conversion efficiency of the xylan components of these agricultural residues catalyzed by acetic acid before and after BEE and EE. As shown in Fig. 2a-d, after BEE and EE, the maximum XXF of CC, SB, WS, and PS was $70.71 \%, 90.75 \%, 84.84 \%$, and $39.08 \%$, respectively, while the XXF of CC, SB, WS, and PS only catalyzed by acetic acid was $55.13 \%, 74.36 \%, 61.19 \%$, and $35.70 \%$. Consequently, the solvent extraction of agricultural residues intensified the hydrolysis of xylan, which improved the acetic acid catalytic efficiency of xylan.

\section{Effect of extraction on the enzymatic hydrolysis of cellulose}

Hemicellulose was generally considered as one of the important physical barriers for enzymatic hydrolysis of cellulose [45]. During the previous stage of acetic acid catalysis, most of the hemicellulose xylan components from CC, SB, WS, and PS have been removed. We enzymatically hydrolyzed the solid residues of acetic acid treatment of the four agricultural residues, before and after extraction using cellulase to study the impact of BEE and EE on enzymatic hydrolyzability of cellulose. Fig. 3a-d shows the 
enzymatic hydrolysis yields of the four agricultural residues. For CC, SB, WS, and PS without extraction, the maximum enzymatic hydrolysis yields were $99.90 \%, 84.84 \%$, $79.96 \%$, and $23.34 \%$, respectively, after $108 \mathrm{~h}$ of enzymatic hydrolysis of the acetic acid catalyzed solid residues. However, the acetic acid catalyzed solid residues of CC, SB, WS, and PS after BEE obtained the highest enzymatic hydrolysis yields of $100 \%$, $86.92 \%, 85.48 \%$, and $23.73 \%$, respectively within $108 \mathrm{~h}$ of enzymatic hydrolysis. In simple terms, the removal of aliphatic compounds from four agricultural residues by BEE slightly improved the enzymatic hydrolyzability of the corresponding solid residues. Additionally, due to the differences in lignin content and structural characteristics between herbaceous plants and woody plants, the enzymatic hydrolyzability of poplar was much worse than that of the three gramineous plants, i.e., $\mathrm{CC}, \mathrm{SB}$, and WS. The maximum enzymatic hydrolysis yields of acetic acid catalyzed solid residues from CC, SB, WS, and PS after EE was 100\%, 87.51\%, 80.66\%, and $26.71 \%$, respectively, after enzymatic hydrolysis for $108 \mathrm{~h}$. Similarly, the enzymatic hydrolyzability of materials after EE also improved compared with the raw materials without extraction. As can be seen from Fig. 3a, although the improvement in the enzymatic hydrolyzability of the four agricultural residues by BEE and EE was not obvious, the improvement of the enzymatic hydrolyzability of the $\mathrm{CC}$ by solvent extraction could be considered to be relatively prominent among the four agricultural residues. The enzymatic hydrolysis yield of acetic acid catalyzed solid residues from $\mathrm{CC}$ after BEE or EE and $60 \mathrm{~h}$ of enzymatic hydrolysis was the same as that obtained after $108 \mathrm{~h}$ of enzymatic hydrolysis. The increase in enzymatic hydrolysis rate of CC 
was not only due to the crystallinity and specific surface area of cellulose itself [46], but also due to the largest increase in XXF of CC after BEE or EE (as shown in Fig. 2a). This indicated that $\mathrm{CC}$ had the highest increase in xylan dissolution rate, which indirectly improved the enzymatic hydrolyzability of cellulose from CC.

However, there was no significant improvement in the enzymatic hydrolyzability of subsequent solid residues after BEE and EE of agricultural residues. As previously described, the surface wax components of the agricultural residues were effectively extracted by BEE and EE, which increased the accessibility of hemicellulose. However, the enzymatic hydrolyzability of cellulose was affected by a variety of physical and chemical factors, and lignin was considered as one of the main obstacles to the inertness of enzymatic hydrolysis of cellulose [44,47,48], while BEE and EE could only partially remove them. Therefore, the extraction and dissolution of aliphatic compounds mainly affected the directional degradation of xylan but has no obvious effect on the enzymatic hydrolyzability of cellulose.

\section{Mass balance calculation of EE technology in biorefinery of agricultural residues}

Overall, BEE and EE had a greater positive impact on CC, SB, and WS compared with PS. For WS with more wax, BEE was more effective than EE alone in increasing the XOS yield. Therefore, solvent extraction to remove the aliphatic compounds could promote the biorefinery of agricultural residues. However, benzene is a carcinogenic toxic substance, which is not suitable for producing edible XOS. Moreover, the addition of benzene to ethanol increased the cost of the extraction solvent. Thus, it was more reasonable to choose EE as an auxiliary treatment method for the biorefinery of grass 
materials while maintaining a balance of efficiency, safety, and cost. Next, we performed a comprehensive evaluation of $\mathrm{CC}, \mathrm{SB}$ and WS after EE. The xylan degradability and cellulose enzyme hydrolyzability of the agricultural residues before and after extraction of the aliphatic compounds were taken as evaluation indexes. Mass balance was based on $100 \mathrm{~g} \mathrm{CC}, \mathrm{SB}$, and WS respectively. Fig. 4 lists the calculation results of each materials. CC, SB, and WS were extracted with ethanol and then subjected to acetic acid acidolysis to obtain $11.68 \mathrm{~g}, 11.03 \mathrm{~g}$, and $7.71 \mathrm{~g}$ XOS respectively. The pretreated solid residues were subjected to enzymatic hydrolysis to obtain $31.30 \mathrm{~g}, 29.48 \mathrm{~g}$, and $26.91 \mathrm{~g}$ glucose respectively. When the ethanol extractives were added back to the materials after extraction and mixed for acidolysis with acetic acid, $12.50 \mathrm{~g}, 12.18 \mathrm{~g}$, and $8.67 \mathrm{~g}$ XOS were obtained from CC, SB, and WS respectively. Therefore, it means that EE can effectively optimize the acetic acid degradation rate of xylan in agricultural residues to obtain a high XOS yield. The readdition of ethanol extractives was also conducive to the dissolution of XOS. The existence of xylose and furfural as two by-products confirmed the high dissolution rate of xylan. At the same time, cellulose was mostly converted into glucose by enzymatic hydrolysis. In summary, EE and the re-addition of extractives provide an auxiliary method for efficiently obtaining high value-added XOS and fermentable monosaccharides from agricultural residues.

\section{Conclusions}

Organic solvent extraction was used to study the effect of aliphatic compounds on the acidolysis and enzymatic hydrolyzability of four agricultural residues. We found 
that removing the aliphatic compounds effectively improved the xylan degradation ability and had a minor impact on the enzymatic hydrolyzability of cellulose. Organic solvent extraction has a more significant optimization effect on herbaceous plants than on hardwood. EE was considered to be an effective and appropriate pretreatment auxiliary method because it was safer and more environmentally-friendly than BEE. Overall, organic solvent extraction technology provided a promising direction for the industrial production of XOS from herbaceous xylan.

\section{Methods}

\section{Materials}

CC, WS, and PS were procured from the Jiangsu Province of China, while SB was procured from the Hainan Province of China. All materials were crushed into small particles of 20-80 mesh size by a plant grinder (A 11 basic Analytical mill) and were air-dried for a week to maintain the moisture content below $10 \%$. Next, the contents of glucan, xylan, araban, and lignin in the four typical agricultural residues were determined by following the National Renewable Energy Laboratory method [49], as shown in Table 3.

\section{Soxhlet extraction of agricultural residues}

A Soxhlet extractor (1 L; self-built) was used for extracting four types of agricultural residues using a benzene-ethanol solution (volume ratio 2:1 (v/v)) and an ethanol solution, separately at $135^{\circ} \mathrm{C}$ for $6 \mathrm{~h}[50]$. Based on the liquid loading capacity of the extraction equipment, a solid-liquid ratio of 1:37.5 (w/v) was used, and only 20 $\mathrm{g}$ of the dry substrate was loaded for each extraction. After extraction, the agricultural 
residues were placed in a fume hood overnight for evaporation to remove residual organic solvents, and the remaining liquid was stored at room temperature.

\section{Pretreatment of agricultural residues with acetic acid}

The acetic acid pretreatment of agricultural residues was performed in a $30 \mathrm{~mL}$ stainless-steel tube $(\Phi 30 \mathrm{~mm} \times 85.0 \mathrm{~mm})$ and capped with screw cap. The total reaction solution volume was $15 \mathrm{~mL}$. Using a solid-liquid ratio of 1:10 (w/v), $1.5 \mathrm{~g}$ of absolute dry matter was mixed with the diluted acetic acid solution. After soaking for one hour at room temperature, the stainless-steel tube was immersed in an electrothermal thermostatic oil tank (Digital oil bath HH-SA, Jintan Youlian Instrument Research Institute, Changzhou, China) to perform the reaction. The reaction conditions were determined based on the difficulty in processing the poplar material and was based on previous literature. The reaction was carried out at $170^{\circ} \mathrm{C}$ for $20 \mathrm{~min}$ with an acetic acid concentration of $5 \%(\mathrm{v} / \mathrm{v})[13,18,22]$. After the reaction was terminated, the stainlesssteel reaction tube was immersed in cold water and cooled rapidly, followed by the phase separation of the acetic acid mixture of lignocelluloses. Next, the concentration of xylan degradation products, such as XOS, xylose, furfural, etc. in the liquid was determined, and the solid residue was washed with tap water thoroughly and stored at $4^{\circ} \mathrm{C}$

\section{Re-addition of extractives}

The organic solvent extraction liquid of the four materials was placed in a fume hood overnight to volatilize and remove the organic solvents to obtain dry solid extractive. The re-addition of the dried solid extractive was also carried out following 
the process conditions in section 2.3 , that is, $1.5 \mathrm{~g}$ of dry matter (including dry solid extractive and materials after extraction) and $15 \mathrm{~mL} 5 \%(\mathrm{v} / \mathrm{v})$ acetic acid mixed acidolysis for $20 \mathrm{~min}$ at $170^{\circ} \mathrm{C}$. According to the Soxhlet extraction ratio of $1: 37.5$ $(\mathrm{w} / \mathrm{v})$, the volume of extraction liquid corresponding to $1.5 \mathrm{~g}$ dry matter was determined. After removing the organic solvent in the certain volume of the extraction liquid, the dry solid extractive was collected and re-added to the corresponding extracted samples to perform the above acetic acid pretreatment.

\section{Enzymatic hydrolysis of solid residues}

The solid residues after pretreatment with acetic acid were washed thoroughly with water to remove impurities, such as polysaccharides, monosaccharides, and acids. The solid residues, $0.05 \mathrm{~mol} / \mathrm{L}$ citrate buffer, and diluted cellulase solution (243.48 FPIU/g and $384.2 \mathrm{mg}$ protein/mL, Cellic CTec2, Novozymes, Sigma Co., Shanghai, China) were mixed at a substrate concentration of $5 \%(\mathrm{w} / \mathrm{v})$ in a $50 \mathrm{~mL}$ centrifuge tube, based on the glucan in the pretreated solids, the enzyme loading concentration of $20 \mathrm{FPIU} / \mathrm{g}$ glucan [11]. Tetracycline $(0.2 \%(\mathrm{w} / \mathrm{v}))$ was added to avoid microbial contamination during enzymatic hydrolysis. The enzymatic hydrolysis was performed at $150 \mathrm{rpm}$ for $108 \mathrm{~h}$ in a thermostatic oscillator (CLASSIC C24, NEW BRUNSWICK SCIENTIFIC CO., INC. Edison, New Jersey, USA) at $\mathrm{pH} 4.8$ and $50^{\circ} \mathrm{C}$. After the reaction was complete, the enzymatic hydrolysates were centrifuged, and the supernatant was collected to detect the concentration of glucose and cellobiose.

\section{Analytical method}


lignin, were measured by following the standard method of NREL [49]. The chemical

compositions of the extraction liquids were determined by triple quadrupole gas

chromatography-mass spectrometry (GC-MS, Agilent 7000B, Thermo Fisher Scientific

Trace ISQ). The constant dry weight of the extractives was determined in a $30^{\circ} \mathrm{C}$ oven

to obtain a constant weight to prevent the loss of volatile contents. The polysaccharides, monosaccharides, and inhibitors in the dried extractives were detected using NREL-

HPLC. The degradation products, such as monosaccharides, furfural, and hydroxymethyl furfural were detected by high-performance liquid chromatography 
$478=\frac{\mathrm{XOS}(\mathrm{X} 2-\mathrm{X} 6) \text { in acetic acid hydrolysate }(\mathrm{g})}{\text { initial xylan content in raw materials }(\mathrm{g})}$

$479 \times 100 \%$

480 Yield of xylan degradation chemicals(\%)

$481=\frac{\text { Degradation chemicals of xylan in acetic acid hydrolysate }(\mathrm{g})}{\text { initial xylan content in raw materials }(\mathrm{g})}$

$482 \times 100 \%$

483 Yield of glucan degradation chemicals(\%)

$484=\frac{\text { Degradation chemicals of glucan in acetic acid hydrolysate }(\mathrm{g})}{\text { initial glucan content in materials }(\mathrm{g})}$

$485 \times 100 \%$

486 Enzymatic hydrolysis yield(\%)

$487=\frac{(\text { Glucose }+ \text { cellobiose }) \text { in enzymatic hydrolysate }(\mathrm{g}) \times 0.9}{\text { glucan content in solid residue after acetic acid acidolysis }(\mathrm{g})}$

$488 \times 100 \%$

489 The relative increase of XOS (\%)

$490=\frac{\text { XOS yield (BEE or EE or re-addition of extractives) }- \text { XOS yield (raw material) }}{\text { XOS yield (raw material) }}$

$491 \times 100 \%$

492 


\section{List of abbreviations}

494

495

496

497

498

499

500

501

502

503

504

505

506

507

508

509

510

511

XOS: xylo-oligosaccharides; CC: corncob; WS: wheat straw; SB: sugarcane bagasse;

PS: poplar sawdust; BEE: benzene-ethanol extraction; EE: ethanol extraction; XXF:

XOS + Xylose + Furfural

\section{Declarations}

Ethics approval and consent to participate

Not applicable

\section{Consent for publication}

Not applicable

\section{Availability of data and materials}

All data generated and analyzed in this study are included in this published article.

\section{Competing interests}

The authors declare that they have no competing interests

\section{Funding}

This work was supported by the National Key R\&D Program of China

(2017YFD0601001)

\section{Authors' contributions}

JMG and KXH developed the idea for the study. JMG and RC performed the research. JMG conducted the data analysis and prepared the manuscript. YX and JHZ helped to revise the manuscript. All authors read and approved the final manuscript.

\section{Acknowledgements}


515 The research was supported by the National Key R\&D Program of China 516 (2017YFD0601001), and the Key Research and Development Program of Jiangsu 517 province in China (BE2015758)

518 


\section{References}

520

[1] Chundawat SPS, Beckham GT, Himmel ME, Dale BE. Deconstruction of Lignocellulosic Biomass to Fuels and Chemicals. Annu Rev Chem Biomol. 2011; 2:121-145. https://doi.org/10.1146/annurev-chembioeng-061010-114205.

[2] Menon V, Rao M. Trends in bioconversion of lignocellulose: Biofuels, platform chemicals \& biorefinery concept. Prog Energ Combust. 2012; 38: 522-550. https://doi.org/10.1016/j.pecs.2012.02.002.

[3] Mosier N, Wyman C, Dale B, Elander R, Lee YY, Holtzapple M, Ladisch M. Features of promising technologies for pretreatment of lignocellulosic biomass. $\begin{array}{llll}\text { Bioresource } & \text { Technol. } & \text { 2005; } & \text { 673-686. }\end{array}$ https://doi.org/10.1016/j.biortech.2004.06.025.

[4] Karimi K, Shafiei M, Kumar R. Progress in Physical and Chemical Pretreatment of Lignocellulosic Biomass. Biofuel Technologies. 2013; P: 53-96. https://doi.org/10.1007/978-3-642-34519-7-3.

[5] Kumar R, Tabatabaei M, Karimi K, Horváth IS. Recent updates on lignocellulosic biomass derived ethanol-A review. Biofuel Research Journal. 2016; 3: 347-356. https://doi.org/10.18331/BRJ2016.3.1.4.

[6] Loow YL, Wu TY, Tan KA, Lim YS, Wen HT. Recent Advances in Application of Inorganic Salt Pretreatment for Transforming Lignocellulosic Biomass into Reducing Sugars. J Agr Food Chem. 2015; 63: 8349. https://doi.org/10.1021/acs.jafc.5b01813. 
[7] Zhang X, Zhang W, Lei F, Yang S, Jiang J. Coproduction of xylo-oligosaccharides and fermentable sugars from sugarcane bagasse by seawater hydrothermal $\begin{array}{lllll}\text { pretreatment. } & \text { Bioresource } & \text { Technol 2020; 309: } & \end{array}$ https://doi.org/10.1016/j.biortech.2020.123385.

[8] Qing Q, Li H, Kumar R, Wyman CE. Xylooligosaccharides Production, Quantification, and Characterization in Context of Lignocellulosic Biomass Pretreatment. Aqueous Pretreatment of Plant Biomass for Biological and Chemical Conversion to Fuels and Chemicals. 2013; 391-415. https://doi.org/10.1002 /594 9780470975831.ch19.

[9] Kumar R, Wyman CE. The impact of dilute sulfuric acid on the selectivity of xylooligomer depolymerization to monomers. Carbohyd Res. 2008; 343: 290-300. https://doi.org/10.1016/j.carres.2007.10.022.

[10]Parajó JC, Garrote G, Cruz JM, Dominguez H. Production of xylooligosaccharides by autohydrolysis of lignocellulosic materials. Trends Food Sci Tech. 2004; 15: 115-120. https://doi.org/10.1016/j.tifs.2003.09.009.

[11]Zhang H, Xu Y, Yu S. Co-production of functional xylo-oligosaccharides and fermentable sugars from corncob with effective acetic acid prehydrolysis. $\begin{array}{llll}\text { Bioresource } & \text { Technol. } & 2017 ; & \text { 343-349. }\end{array}$ https://doi.org/10.1016/j.biortech.2017.02.094.

[12]Zhang H, Zhou X, Xu Y, Yu S. Production of Xylo-oligosaccharides from Waste Xylan, Obtained from Viscose Fiber Processing, by Selective Hydrolysis Using 
Concentrated Acetic Acid. J Wood Chem Technol. 2016; 37: 1-9. https://doi.org/10.1080/02773813.2016.1214154.

563

[13]Huang K, Lalitendu D, Guo J, Xu Y. Catalytic valorization of hardwood for enhanced xylose-hydrolysate recovery and cellulose enzymatic efficiency via synergistic effect of $\mathrm{Fe} 3+$ and acetic acid. Biotechnol Biofuels. 2019; 248. https://doi.org/10.1186/s13068-019-1587-4.

[14]Buruiana CT, Gómez B, Vizireanu C, Garrote G. Manufacture and evaluation of xylo-oligosaccharides from corn stover as emerging prebiotic candidates for human health. Lwt-Food Sci Technol. 2017; 77: 449-459. https://doi.org/10.1016/j.lwt.2016.11.083.

[15] Santos A, Mauro MS, Diaz DM. Prebiotics and their long-term influence on the microbial populations o the mouse bowel. Food Microbiol. 2006; 23: 498-503. https://doi.org/10.1016/j.fm.2005.07.004.

[16] Jain I, Kumar V, Satyanarayana T. Xylo-oligosaccharides: An economical prebiotic from agroresidues and their health benefits. Indian J Exp Biol. 2015; 53: 131-142.

[17]Zhao X, Wang L, Lu X, Zhang S. Pretreatment of corn stover with diluted acetic acid for enhancement of acidogenic fermentation. Bioresource Technol. 2014; 158 : 12-18. https://doi.org/10.1016/j.biortech.2014.01.122.

[18]Guo J, Huang K, Zhang S, Xu Y. Optimization of selective acidolysis pretreatment for the valorization of wheat straw by a combined chemical and enzymatic process. J Chem Technol Biot. 2019; 3: 694-701. https://doi.org/10.1002/jctb.6251. 
[19] Talebnia F, Karakashev D, Angelidaki I. Production of bioethanol from wheat straw: An overview on pretreatment, hydrolysis and fermentation. Bioresource Technol. 2010; 101: 4744-4753. https://doi.org/10.1016/j.biortech.2009.11.080.

[20]Aachary AA, Prapulla SG. Value addition to corncob: Production and characterization of xylo-oligosaccharides from alkali pretreated lignin-saccharide complex using Aspergillus oryzae MTCC 5154. Bioresource Technol. 2009; 100: 991-995. https://doi.org/10.1016/j.biortech.2008.06.050.

[21]Guo J, Cao R, Huang K, Xu Y. Comparison of selective acidolysis of xylan and enzymatic hydrolysability of cellulose in various lignocellulosic materials by a novel xylonic acid catalysis method. Bioresource Technol. 2020; 304. https://doi.org/10.1016/j.biortech.2020.122943.

[22]Huang K, Luo J, Cao R, Su Y, Xu Y. Enhanced xylo-oligosaccharides yields and enzymatic hydrolyzability of cellulose using acetic acid catalysis of poplar sawdust. J Wood Chem Technol. 2018; 39: 371-384. https://doi.org/10.1080/02773813.2018.1500608.

[23]Pambou E, Li Z, Campana M, Hughes A, Clifton L, Gutfreund P, Foundling J, Bell G, Lu JR. Structural features of reconstituted wheat wax films. J R Soc Interface. 2016; 13: 20160396. https://doi.org/10.1098/rsif.2016.0396.

[24]Deswarte FEI, Clark JH, Hardy JJE, Rose PM. The fractionation of valuable wax products from wheat straw using CO2. Green Chem. 2006; 8: 39-42. https://doi.org/10.1039/b514978a. 
603

604

605

606

607

608

609

610

611

612

613

614

[25]Ishiga Y, Upplapapti SR, Mysore KS. Expression analysis reveals a role for hydrophobic or epicuticular wax signals in pre-penetration structure formation of Phakopsora pachyrhizi. Plant Signal Behav. 2013; 8: e26959. https://doi.org/10.4161/psb.26959.

[26] Koch K, Ensikat H. The hydrophobic coatings of plant surfaces: Epicuticular wax crystals and their morphologies, crystallinity and molecular self-assembly. Micron. 2008; 39: 759-772. https://doi.org/10.1016/j.micron.2007.11.010.

[27]Kadar Z, Schultz-Jensen N, Jensen JS, Hansen MAT, Leipold F, Bjerre AB. Enhanced ethanol production by removal of cutin and epicuticular waxes of wheat straw by plasma assisted pretreatment. Biomass Bioenerg. 2015; 81: 26-30. https://doi.org/10.1016/j.biombioe.2015.05.012.

[28]Qi G, Peng F, Xiong L, Lin X, Huang C, Li H, Chen X, Chen X. Extraction and characterization of wax from sugarcane bagasse and the enzymatic hydrolysis of dewaxed sugarcane bagasse. Prep Biochem Biotech. 2016; 47: 276-281. https://doi.org/10.1080/10826068.2016.1224246.

[29] Koch K, Barthlott W, Koch S, Hommes A, Wandelt K, Mamdouh W, De-Feyter S, Broekmann P. Structural analysis of wheat wax (Triticum aestivum, c.v. 'Naturastar' L.): from the molecular level to three dimensional crystals. Planta. 2006; 223: 258270. https://doi.org/10.1007/s00425-005-0081-3.

[30]Fagerstr MA, Kocherbitov V, Westbye P, Bergstr MK, Mamontova V, Engblom J. Characterization of a plant leaf cuticle model wax, phase behaviour of model wax- 
water systems. Thermochim Acta. 2013; 571: 42-52. https://doi.org/10.1016/j.tca.2013.08.025.

[31] Sin EHK, Marriott R, Hunt AJ, Clark JH. Identification, quantification and Chrastil modelling of wheat straw wax extraction using supercritical carbon dioxide. $\mathrm{Cr}$ Chim. 2014; 17: 293-300. https://doi.org/10.1016/j.crci.2013.12.001.

[32] Shanmugasundaram N, Rajendran I. Characterization of raw and alkali-treated mulberry fibers as potential reinforcement in polymer composites. Journal of Reinforced Plastics \& Composites. 2016; 35: 1917953442. https://doi.org/10.1177/0731684415625822.

[33]Hua J, Yang Z, Wang X. Effect of lipases on the surface properties of wheat straw. Ind Crop Prod. 2009; 30: 304-310. https://doi.org/10.1016/j.indcrop.2009.05.009.

[34]Kim BG, Kim H, Hur H, Lim Y, Ahn J. Regioselectivity of 7-O-methyltransferase of poplar to flavones. J Biotechnol. 2006; 126: 241-247. https://doi.org/10.1016/j.jbiotec.2006.04.019.

[35]Joe EJ, Kim BG, An BC, Chong Y, Ahn JH. Engineering of flavonoid Omethyltransferase for a novel regioselectivity. Mol Cells. 2010; 30: 137-141. https://doi.org/10.1007/s10059-010-0098-8.

[36]Kunst L, Samuels AL. Biosynthesis and secretion of plant cuticular wax. Prog Lipid Res. 2003; 42: 51-80. https://doi.org/10.1016/S0163-7827(02)00045-0.

[37]Del Río JC, Prinsen P, Gutiérrez AA. Comprehensive Characterization of Lipids in Wheat Straw. J Agr Food Chem. 2013; 61: 1904-1913. https://doi.org/10.1021/jf304252m. 
646 [38]Hou CT, III RJF. Growth inhibition of plant pathogenic fungi by hydroxy fatty acids. J Ind Microbiol Biot. 2000; 24: 275-276. https://doi.org/10.1038/sj.jim.2900816.

649 [39] Takashi N, Yoko O, Noriko N, Mikiko K, Sakakibara H, Umeda M. Synthesis of Very-Long-Chain Fatty Acids in the Epidermis Controls Plant Organ Growth by Restricting Cell Proliferation. Plos Biol. 2013; 4: e1001531. https://doi.org/10.1371/journal.pbio.1001531.

[40]Nasser RA, Al-Mefarrej HA. Non-Carcinogenic Solvents as Alternative to Benzene for Wood Extractives Determination. Alexandria Science Exchange Journal. 2009; 3: 397-405.

Curr. Opin. Plant Plant 2009; 12: 721-727. https://doi.org/10.1016/j.pbi.2009.09.009.

[43]Rosatella AA, Simeonov SP, Frade RFM, Afonso CAM. 5-Hydroxymethylfurfural

[42] Kabel MA, Carvalheiro F, Garrote G, Avgerinos E, Voragen AGJ. Hydrothermally treated xylan rich by-products yield different classes of xylo-oligosaccharides. Carbohyd Polym. 2002; 50: 47-56. https://doi.org/10.1016/S0144-8617(02)000450. (HMF) as a building block platform: Biological properties, synthesis and synthetic $\begin{array}{llll}\text { applications. } & \mathrm{J} \quad \text { Cheminformatics. } & \text { 2011; } & \text { 13: }\end{array}$ https://doi.org/10.1016/S0144-8617(02)00045-0. 
[44]Liu B, Zhang Z. One-Pot Conversion of Carbohydrates into Furan Derivatives via Furfural and 5-Hydroxylmethylfurfural as Intermediates. Chemsuschem. 2016; 9: 2015-2036. https://doi.org/10.1002/cssc.201600507.

[45]Qing Q, Wyman CE. Supplementation with xylanase and $\hat{I}^{2}$-xylosidase to reduce xylo-oligomer and xylan inhibition of enzymatic hydrolysis of cellulose and pretreated corn stover. Biotechnol Biofuels. 2011; 4: 18-18. https://doi.org/10.1186/1754-6834-4-18.

[46]Ji G, Gao C, Xiao W, Han L. Mechanical fragmentation of corncob at different plant scales: Impact and mechanism on microstructure features and enzymatic hydrolysis. Bioresource Technol. 2016; 205: S0960852416000420. https://doi.org/10.1016/j.biortech.2016.01.029.

[47]Bornscheuer U, Buchholz K, Seibel J. Enzymatic Degradation of (Ligno)cellulose. Angew Chem Int Edit. 2014; 53: 10876-10893. https://doi.org/10.1002/anie.201309953.

[48]Eriksson T, Rjesson JB, Tjerneld F. Mechanism of surfactant effect in enzymatic hydrolysis of lignocellulose. Enzyme Microb Tech. 2002; 31: 353-364. https://doi.org/10.1002/er.1498.

[49] Sluiter JB, Ruiz RO, Scarlata CJ, Sluiter AD, Templeton DW. Compositional Analysis of Lignocellulosic Feedstocks. 1. Review and Description of Methods. J Agric Food Chem. 2010; 58: 9043-9053. https://doi.org/10.1021/jf1008023.

[50]Ma XJ, Cao SL, Yang XF, Lin L, Chen LH, Huang LL. Lignin removal and benzene-alcohol extraction effects on lignin measurements of the hydrothermal 

https://doi.org/10.1016/j.biortech.2013.10.078.

691 


\section{Figure Captions}

693 Figure 1. The comparison of the yields of XOS of four agricultural residues under three 694 conditions: (i) Acidolysis of raw materials with acetic acid; (ii) Acidolysis of the 695 materials after BEE or EE with acetic acid; (iii) Acetic acid acidolysis after the re696 addition of extractives. (a) Corncob; (b) Sugarcane bagasse; (c) Wheat straw; (d) poplar 697 sawdust

698 Figure 2. Degradation mechanism of by-products during the catalysis of various 699 agricultural residues with acetic acid. (a) Corncob; (b) Sugarcane bagasse; (c) Wheat 700 straw; (d) poplar sawdust

701 Figure 3. Enzymatic hydrolysis of solid residues treated with acetic acid from various 702 agricultural residues before and after extraction. (a) Corncob; (b) Sugarcane bagasse; (c) Wheat straw; (d) poplar sawdust

Figure 4. Comparison of the mass balance of the products of acetic acid acidolysis and enzymatic hydrolysis from the agricultural residues after EE 

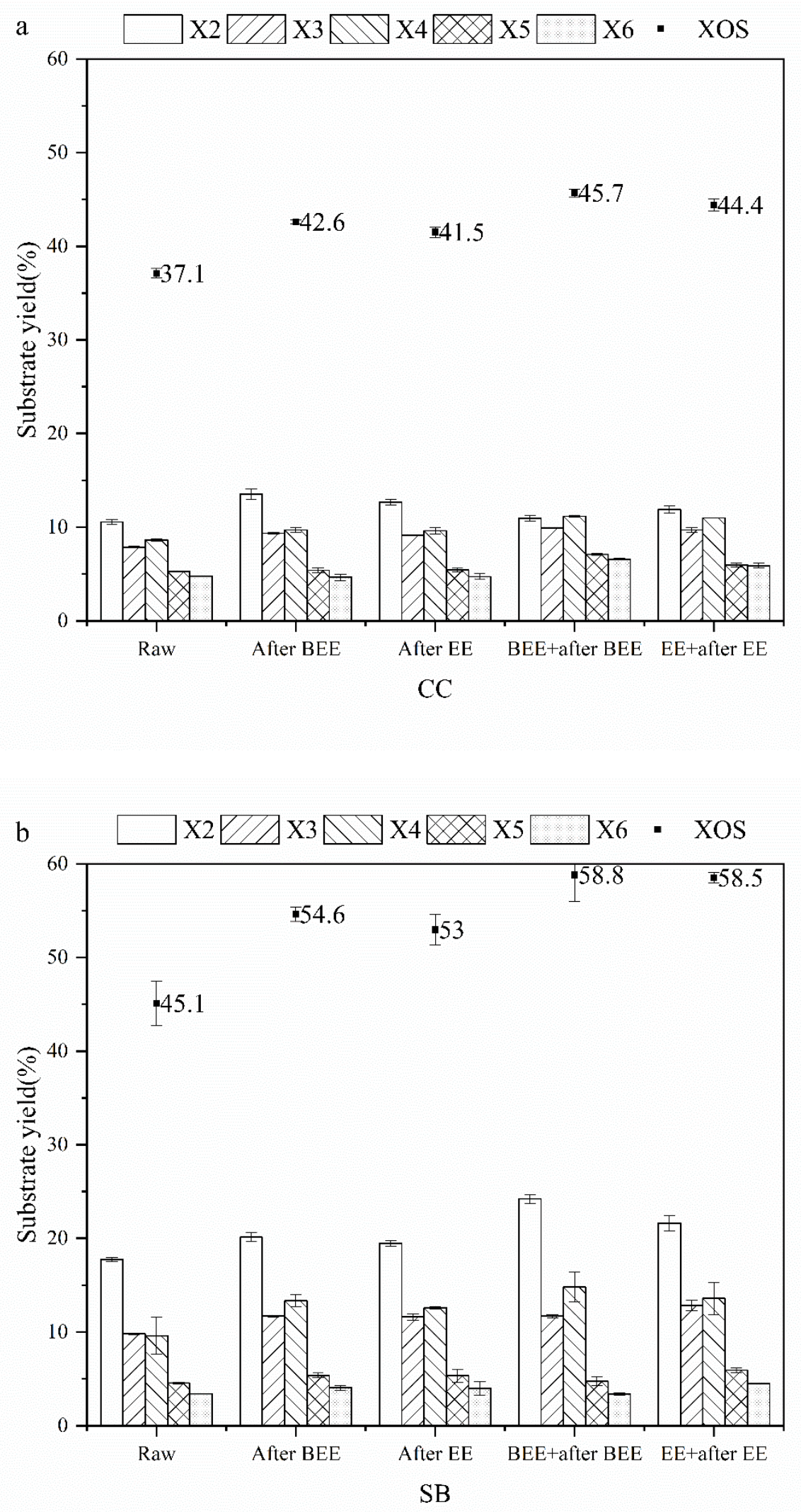


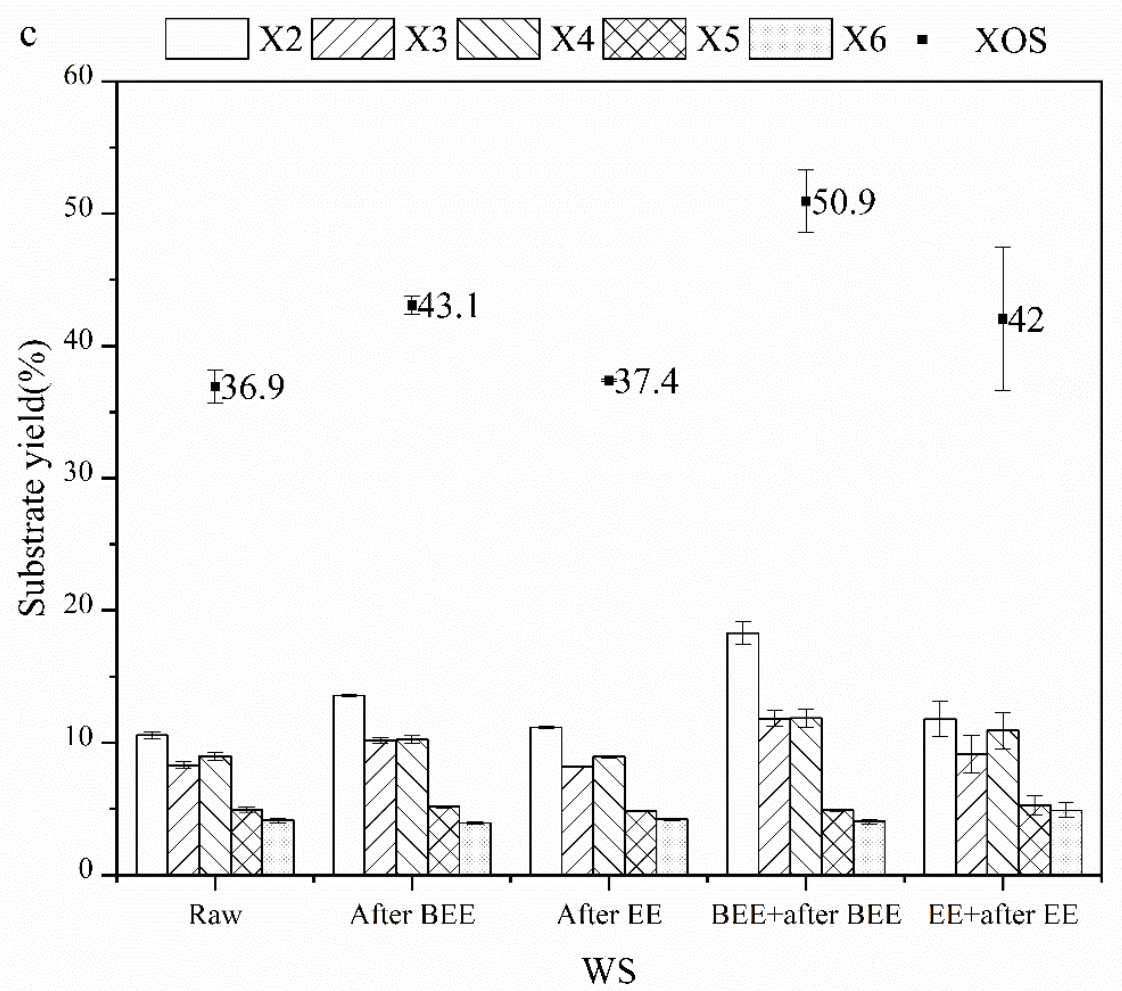

710

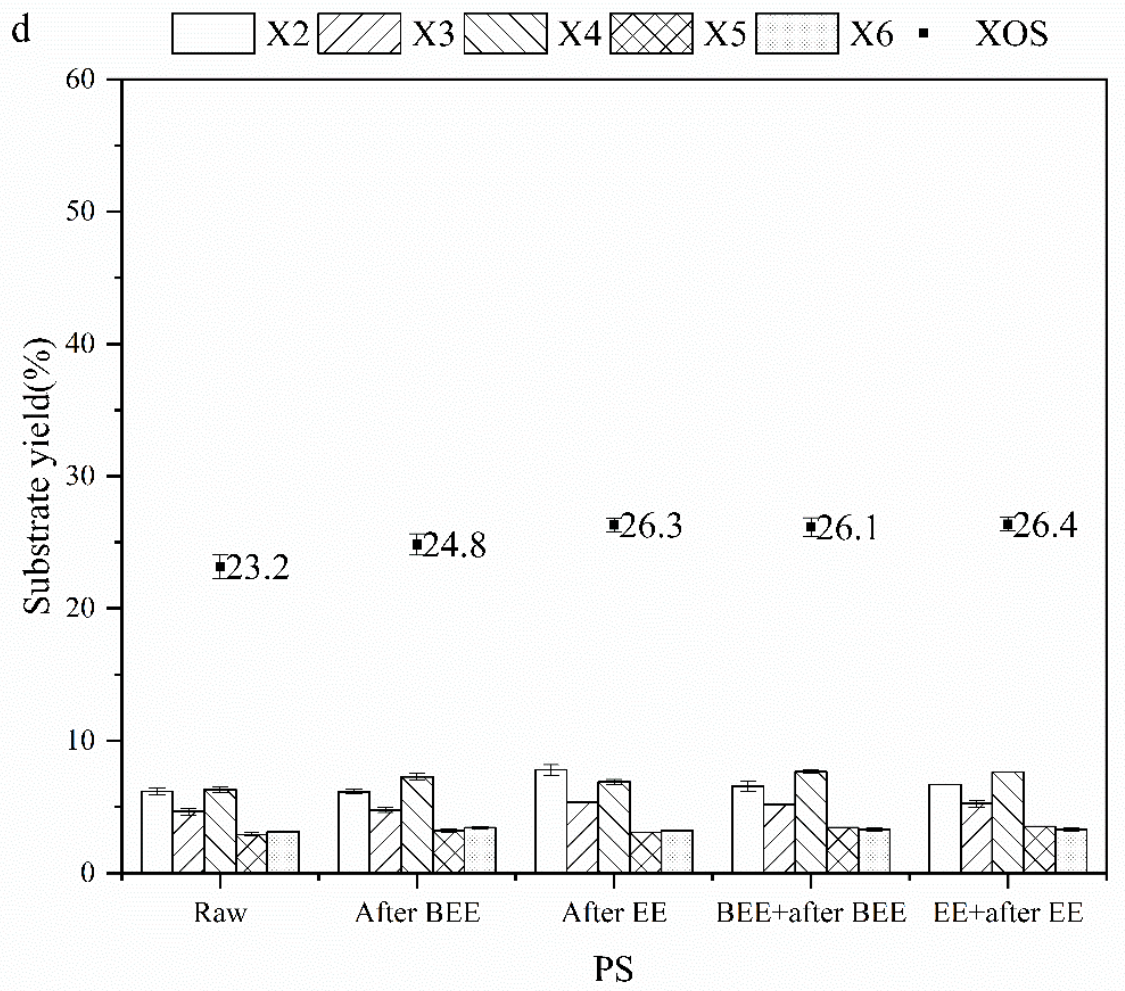



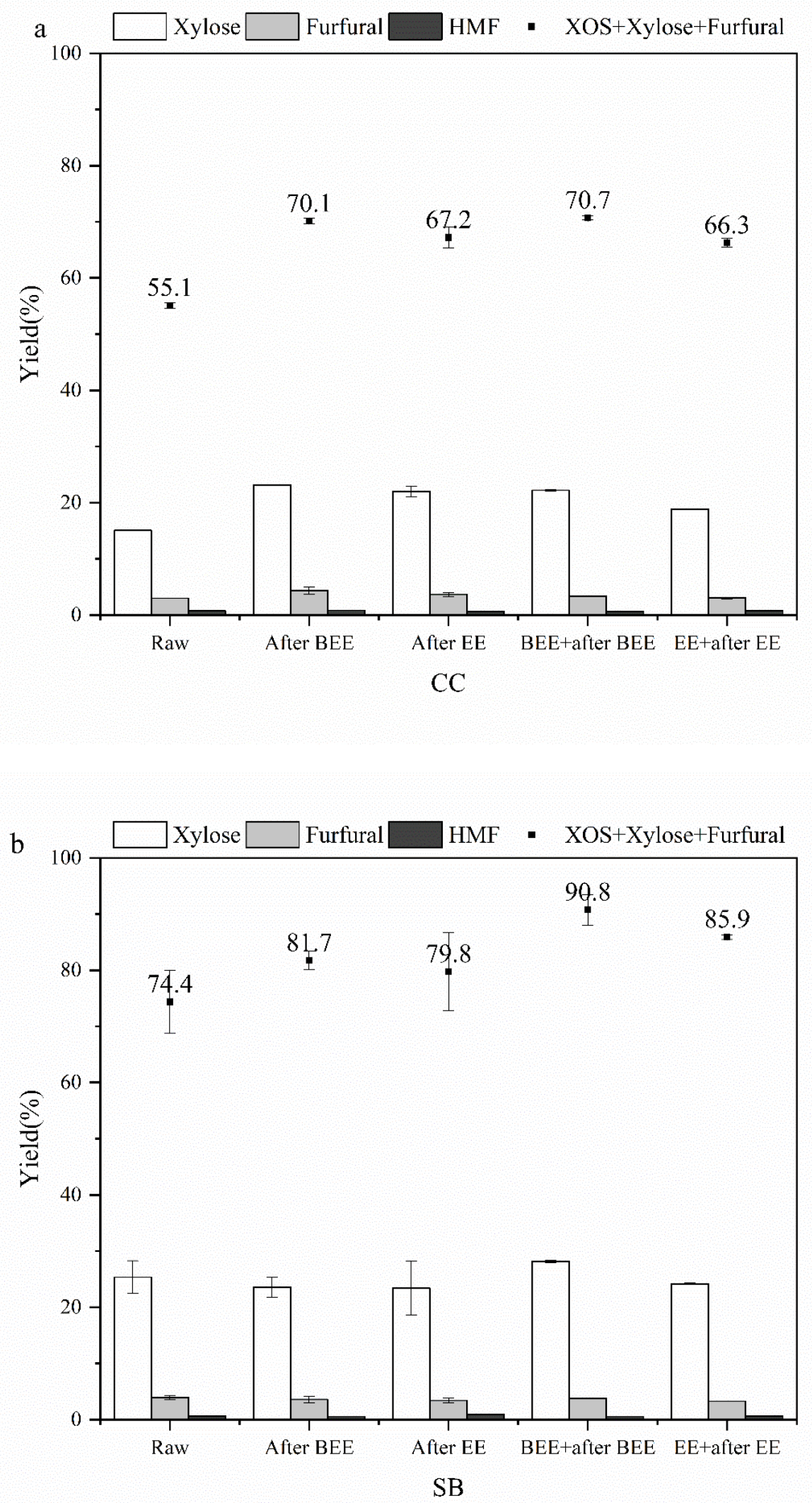


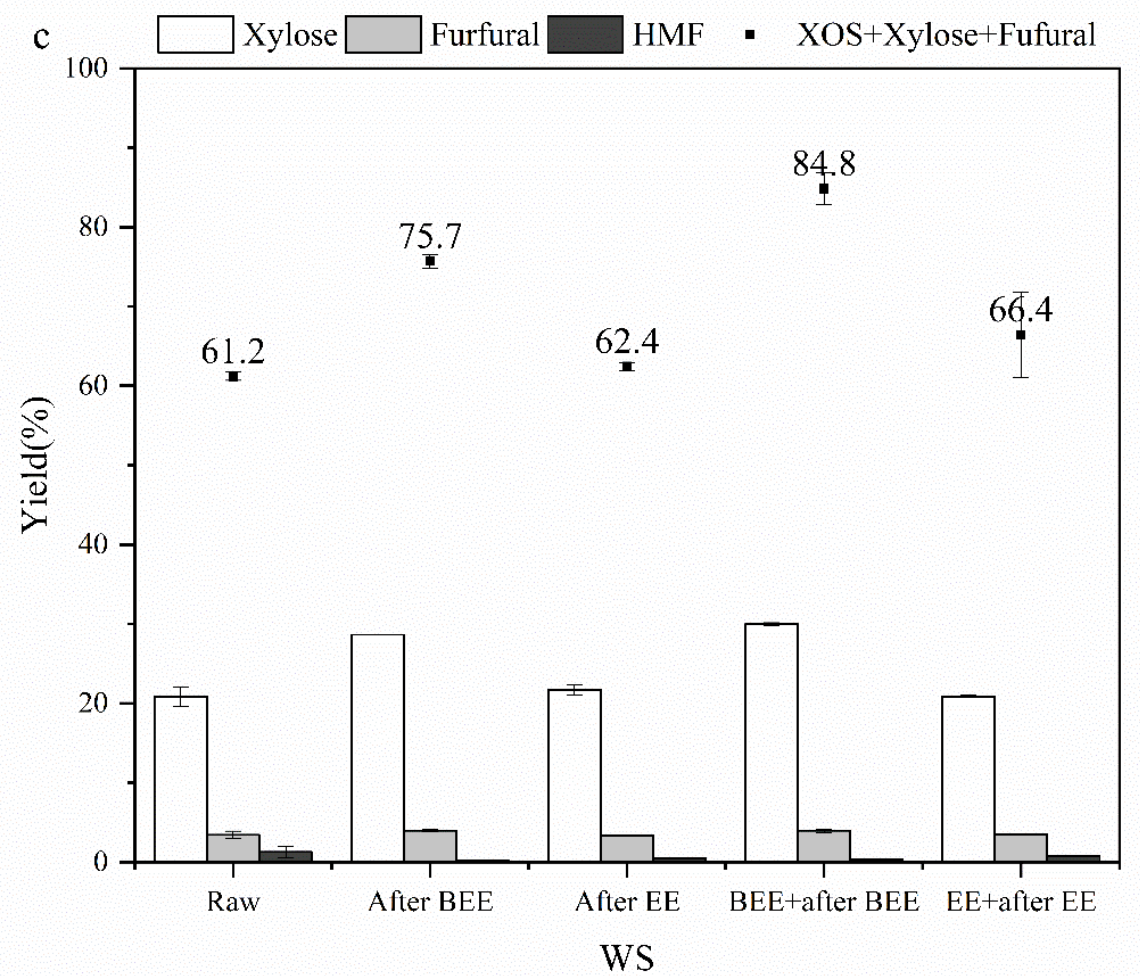

716

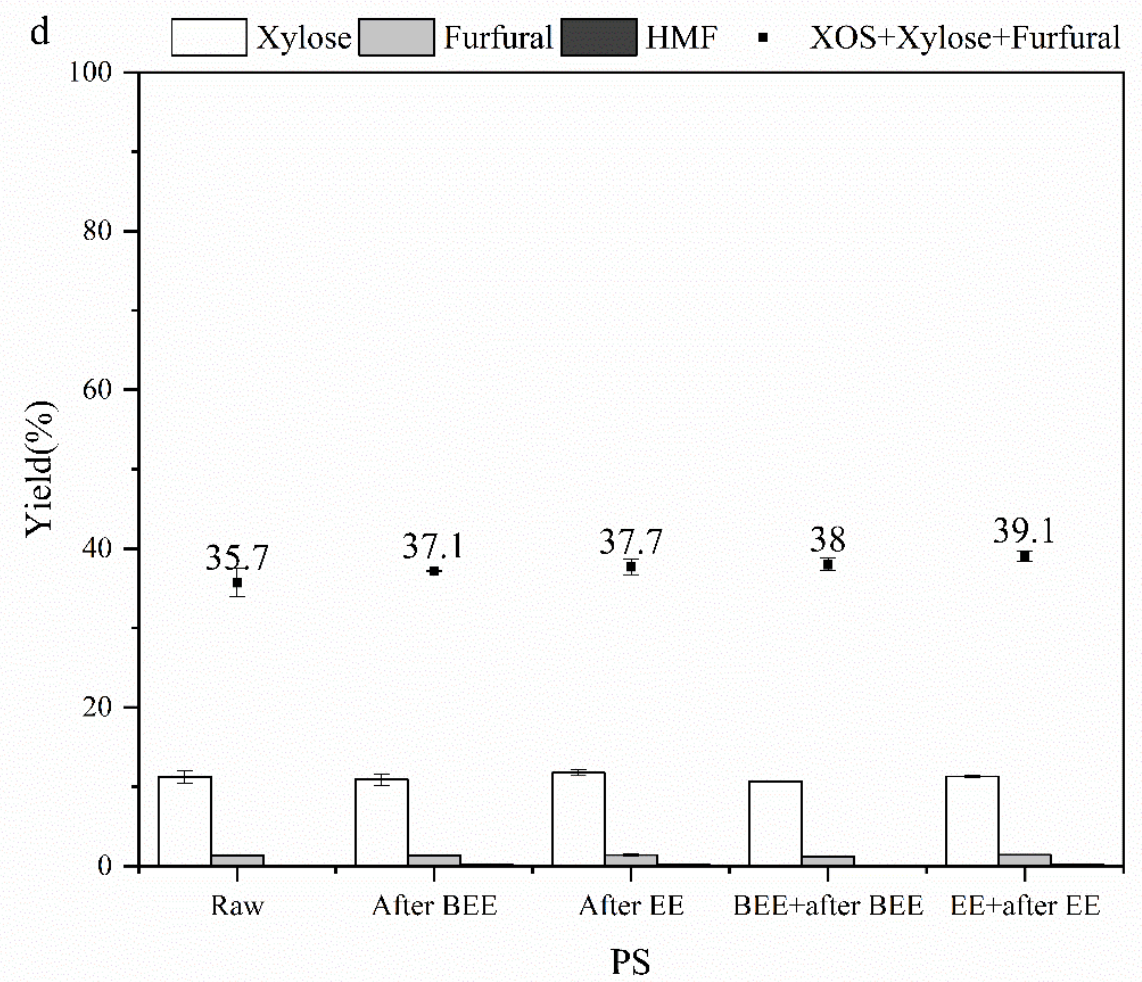




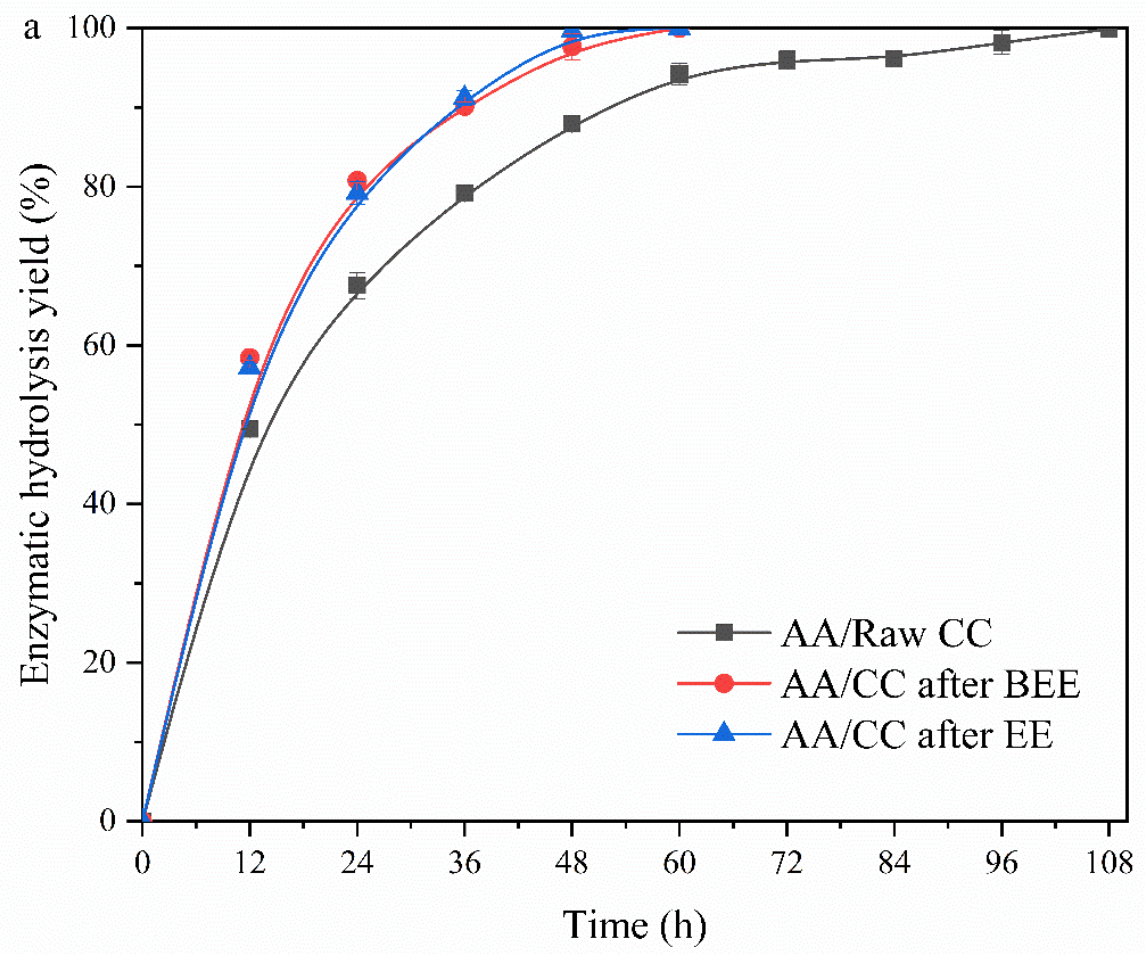

720

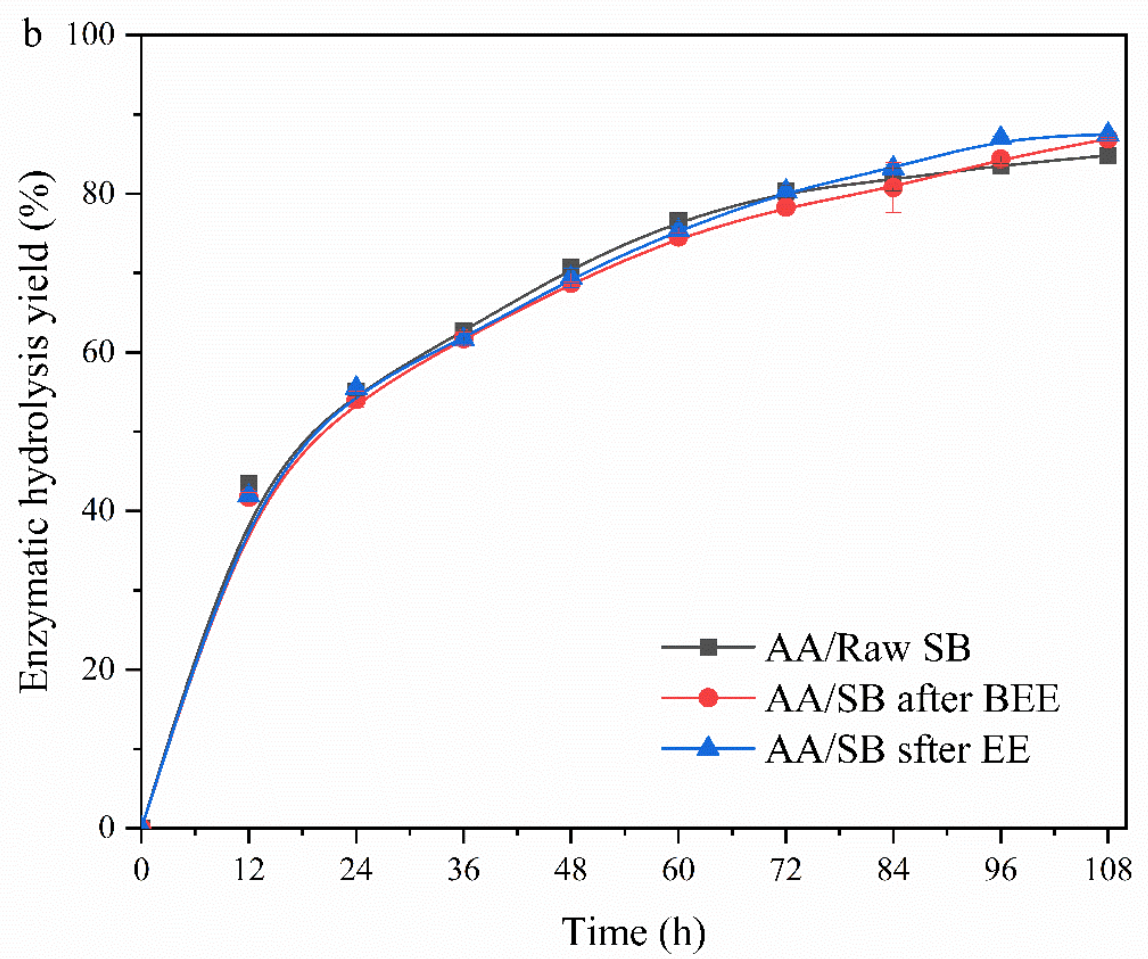




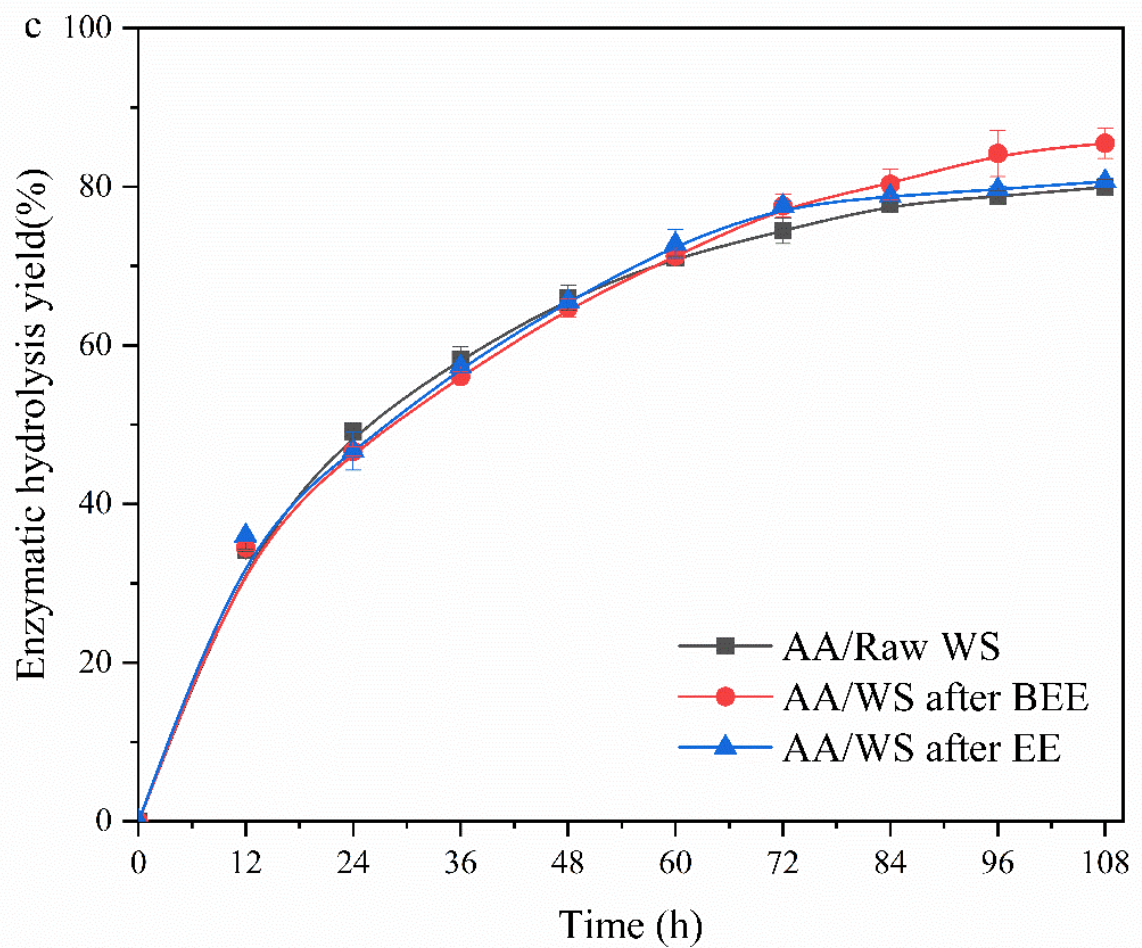

722

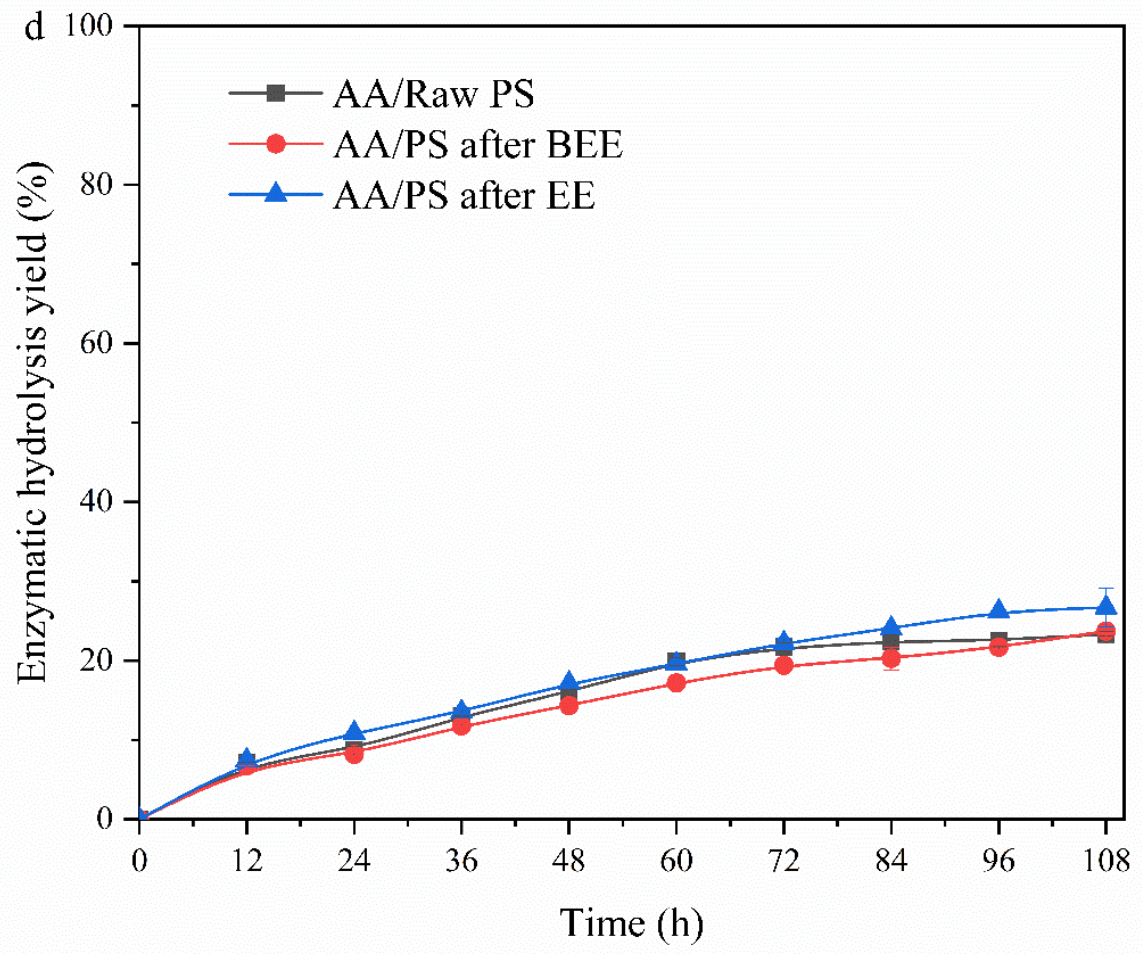




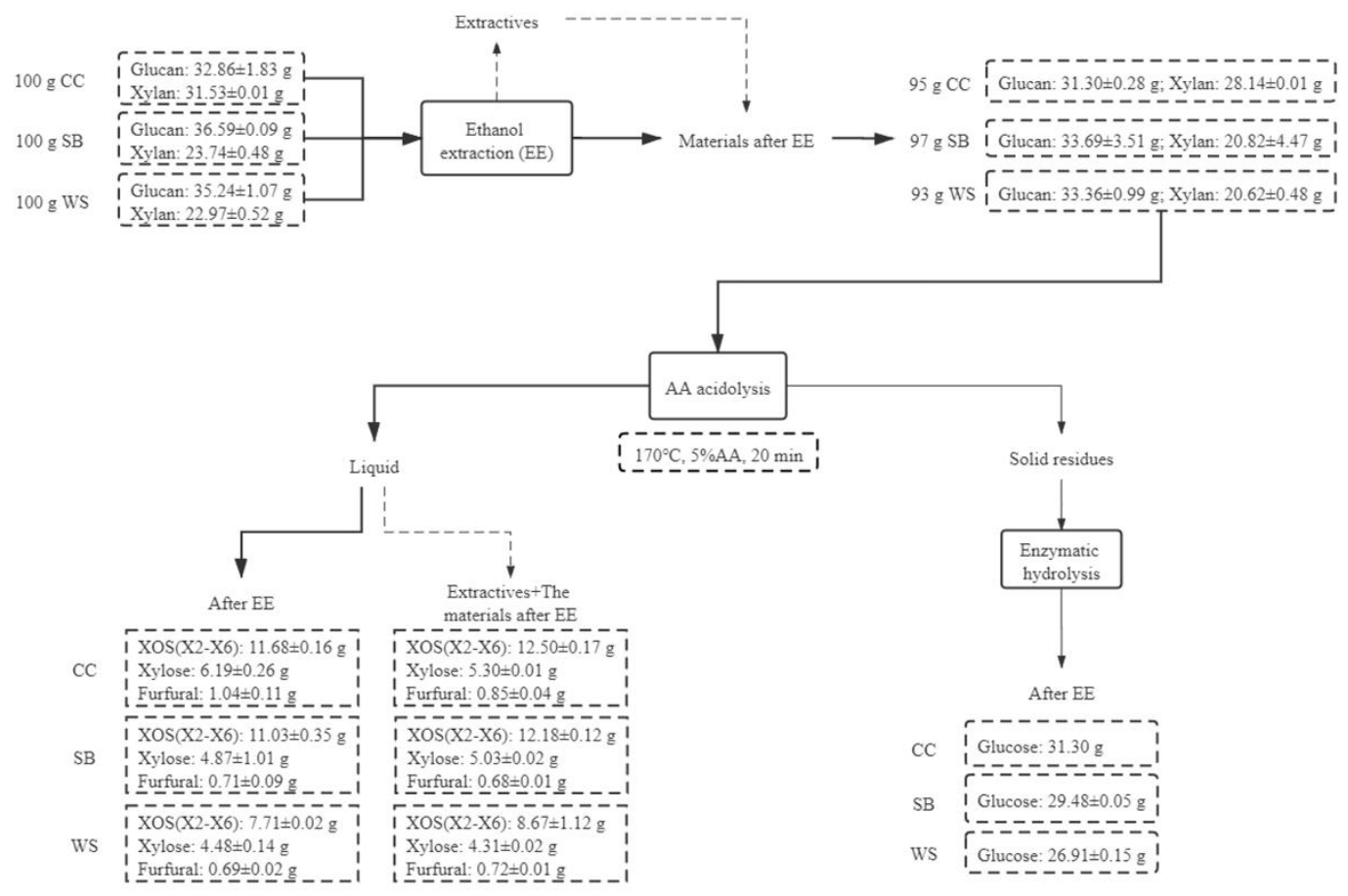


Table 1 Extracted solid and carbohydrate compounds of various agricultural residues

729 Table 2 Composition and abundance of solvent extractives from various agricultural

730 residues by GC-MS detection

731 Table 3 Contents of main components in agricultural residues

732 
Table 1

\begin{tabular}{|c|c|c|c|c|c|c|}
\hline \multirow{3}{*}{ Materials } & \multicolumn{2}{|c|}{ Extraction yield of total solid } & \multicolumn{4}{|c|}{ Carbohydrate compounds of extractives detected by NREL-HPLC } \\
\hline & \multirow{2}{*}{$\mathrm{BEE} / \%$} & \multirow{2}{*}{$\mathrm{EE} / \%$} & \multicolumn{2}{|c|}{ In the benzene-ethanol extractives } & \multicolumn{2}{|c|}{ In the ethanol extractives } \\
\hline & & & Glucose $/ \%$ & Xylose $/ \%$ & Glucose $/ \%$ & Xylose $/ \%$ \\
\hline $\mathrm{CC}$ & 1.60 & 4.28 & $1.38 \pm 0.04$ & $1.42 \pm 0.01$ & $4.33 \pm 0.25$ & $4.98 \pm 0.37$ \\
\hline SB & 1.55 & 2.71 & $1.93 \pm 0.32$ & $4.50 \pm 0.85$ & $4.23 \pm 0.25$ & $6.50 \pm 0.62$ \\
\hline WS & 2.07 & 6.57 & $0.86 \pm 0.04$ & $4.65 \pm 0.28$ & $3.05 \pm 0.02$ & $5.34 \pm 0.14$ \\
\hline PS & 1.22 & 1.41 & $2.09 \pm 0.34$ & $0.85 \pm 0.19$ & $3.87 \pm 0.26$ & $3.10 \pm 0.32$ \\
\hline
\end{tabular}

734 


\begin{tabular}{|c|c|c|c|c|c|c|c|c|c|}
\hline \multirow{3}{*}{ Compounds } & & \multicolumn{8}{|c|}{ Area $(\%)$} \\
\hline & & \multicolumn{4}{|c|}{ Benzene-ethanol extractives } & \multicolumn{4}{|c|}{ Ethanol extractives } \\
\hline & & $\mathrm{CC}$ & SB & WS & PS & $\mathrm{CC}$ & SB & WS & PS \\
\hline \multirow[t]{11}{*}{$n$-fatty acids } & tetradecanoic acid & & & 3.17 & 2.08 & & & & \\
\hline & pentadecanoic acid & 1.58 & 1.31 & & 2.81 & & & & \\
\hline & n-hexadecanoic acid & 34.25 & 57.22 & 23.09 & 44.86 & 3.62 & 7.18 & 9.81 & 4.21 \\
\hline & palmitoleic acid & 4.50 & 7.14 & & & & & & \\
\hline & gamolenic acid & & & & 2.19 & & & & \\
\hline & heptadecanoic acid & & & & 1.33 & & & & \\
\hline & 9,12-octadecadienoic acid & & 19.18 & & 26.06 & & & & \\
\hline & cis-vaccenic acid & 37.98 & & & & & & & \\
\hline & cis-13-octadecenoic acid & & & 1.88 & & & & & \\
\hline & oleic acid & 2.36 & & 2.56 & & & & & \\
\hline & octadecanoic acid & & 2.13 & & 5.68 & & & 1.98 & \\
\hline$n$-fatty alcohols & phytol & & & 3.11 & & & & & \\
\hline \multirow[t]{22}{*}{$n$-alkanes } & 4-methyl-decane & & & & & & 2.01 & 1.66 & 1.61 \\
\hline & 2,6-dimethyl-undecane & & & & & & 1.74 & & \\
\hline & dodecane & & & 3.06 & & & 2.24 & 2.86 & 2.73 \\
\hline & 4,6-dimethyl-dodecane & & & & & & 2.71 & & 2.05 \\
\hline & 2,6,11-trimethyl-dodecane & & & & & & 7.56 & 3.63 & 5.40 \\
\hline & 2,6,10-trimethyl-dodecane & & & & & 2.68 & 1.72 & 3.38 & 6.05 \\
\hline & 2,7,10-trimethyl-dodecane & & & & & & 3.22 & & \\
\hline & tridecane & & & 4.85 & & & & & \\
\hline & tetradecane & & & & & & & 3.35 & \\
\hline & pentadecane & & & & & & 5.78 & & 2.80 \\
\hline & 4-methyl-pentadecane & & & & & & & & 1.67 \\
\hline & hexadecane & & & & & & & 7.48 & \\
\hline & 2,6,10,14-tetramethyl-hexadecane & & & & & & 5.93 & & 5.01 \\
\hline & 2,6,11,15-tetramethyl-hexadecane & & & & & & & 3.29 & 4.02 \\
\hline & 2,6,10,15-tetramethyl-heptadecane & & & & & & 3.22 & 2.14 & 3.02 \\
\hline & heptacosane & & & & & 10.55 & 5.25 & 4.34 & \\
\hline & octadecane & & & & & & & & 5.56 \\
\hline & nonadecane & & & & & & & 3.39 & \\
\hline & heneicosane & & & & & & 5.90 & & \\
\hline & tetracosane & & & & & & 2.33 & & \\
\hline & 2-methyl-hexacosane & & & & & & & 2.59 & 2.19 \\
\hline & hentriacontane & & & & & 5.36 & & & \\
\hline \multirow[t]{3}{*}{ aldehydes } & 9,17 -octadecadienal & & & & 1.96 & & & & \\
\hline & 13-octadecenal & & & 4.81 & & & & & \\
\hline & vanillin & 2.44 & & & & & & 2.39 & \\
\hline \multirow[t]{2}{*}{ ketones } & 6,10,14-trimethyl-2-pentadecanone & & & 11.74 & & & & & \\
\hline & 2-heptadecanone & & & 6.92 & & & & & \\
\hline
\end{tabular}




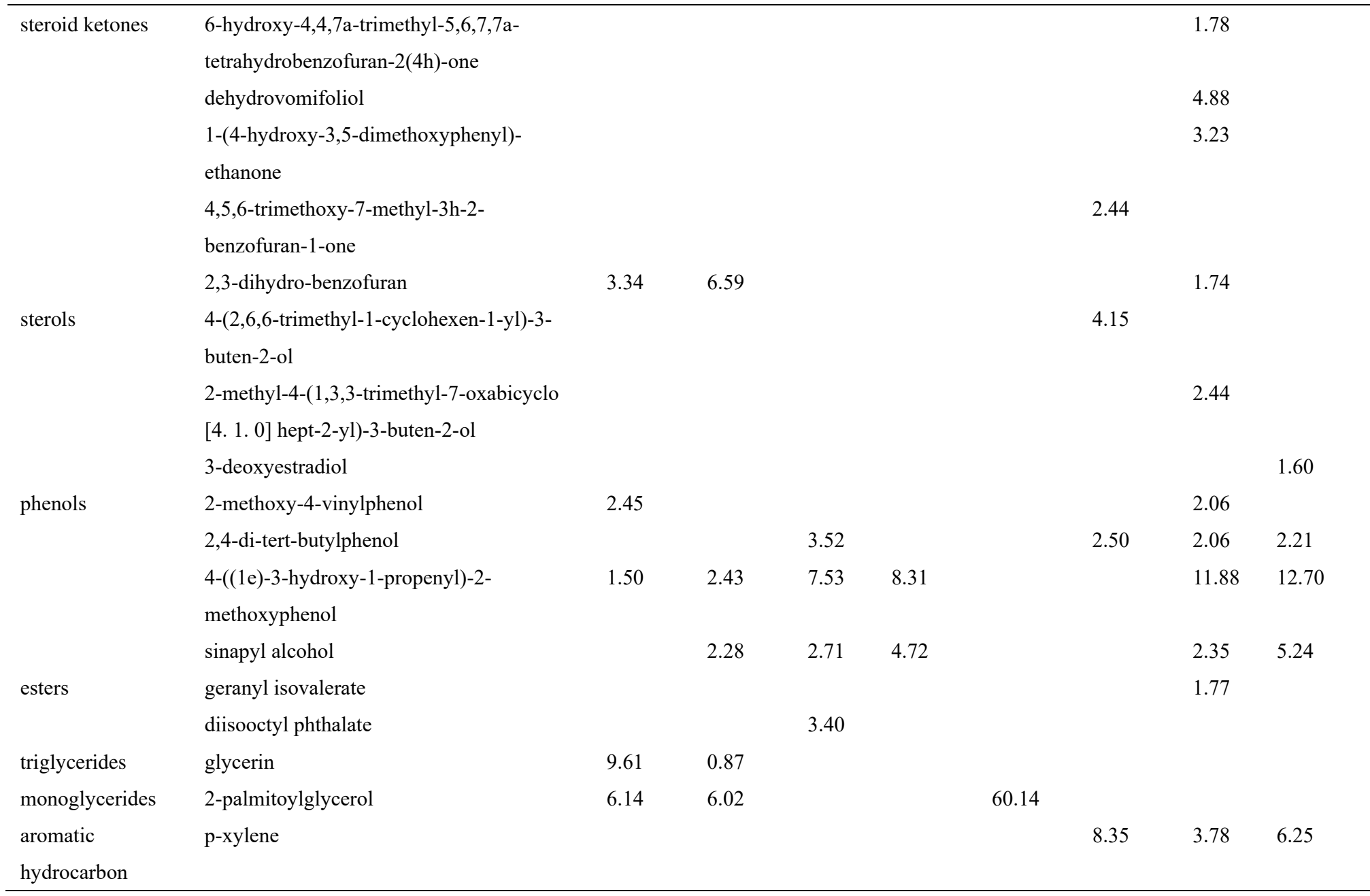


Table 3

\begin{tabular}{llllll}
\hline Materials & Glucan/\% & Xylan/\% & Araban/\% & Acid-soluble lignin/\% & Acid-insoluble lignin/\% \\
\hline CC & $32.86 \pm 1.83$ & $31.53 \pm 0.01$ & $4.68 \pm 0.24$ & $4.42 \pm 0.01$ & $15.86 \pm 0.10$ \\
SB & $36.59 \pm 0.09$ & $23.74 \pm 0.48$ & $4.62 \pm 0.47$ & $2.96 \pm 0.19$ & $16.98 \pm 0.51$ \\
WS & $35.24 \pm 1.07$ & $22.97 \pm 0.52$ & $4.08 \pm 0.73$ & $3.18 \pm 0.04$ & $18.67 \pm 1.48$ \\
PS & $40.07 \pm 0.46$ & $16.99 \pm 0.17$ & $/$ & $2.66 \pm 0.05$ & $23.06 \pm 0.76$ \\
\hline
\end{tabular}

740 


\section{Figures}
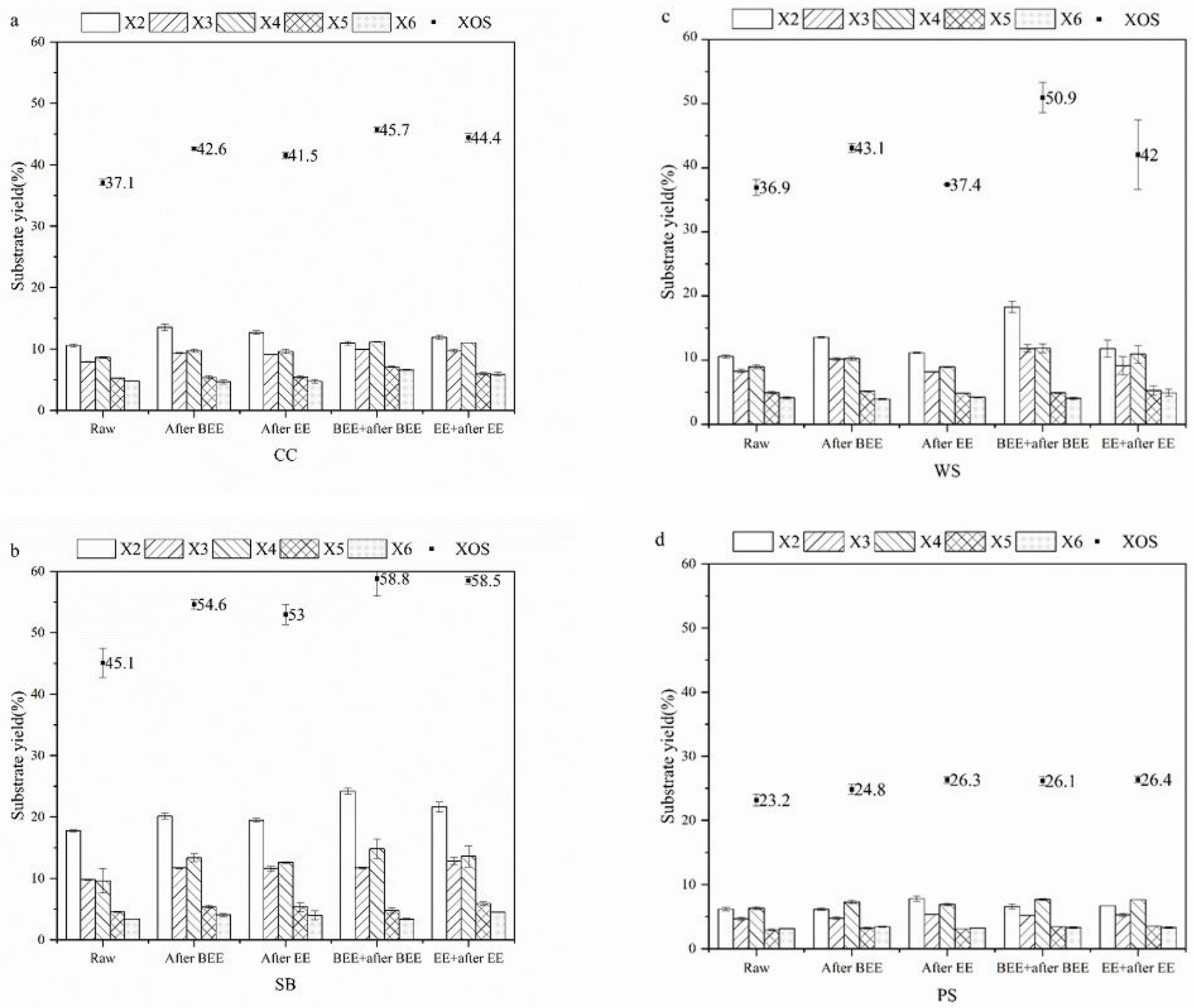

\section{Figure 1}

The comparison of the yields of XOS of four agricultural residues under three conditions: ( $\triangle$ ) Acidolysis of raw materials with acetic acid; ( $(\mathbb{)})$ Acidolysis of the materials after BEE or EE with acetic acid; ( $\mathbb{Z}$ ) Acetic acid acidolysis after the re-addition of extractives. (a) Corncob; (b) Sugarcane bagasse; (c) Wheat straw; (d) poplar sawdust 

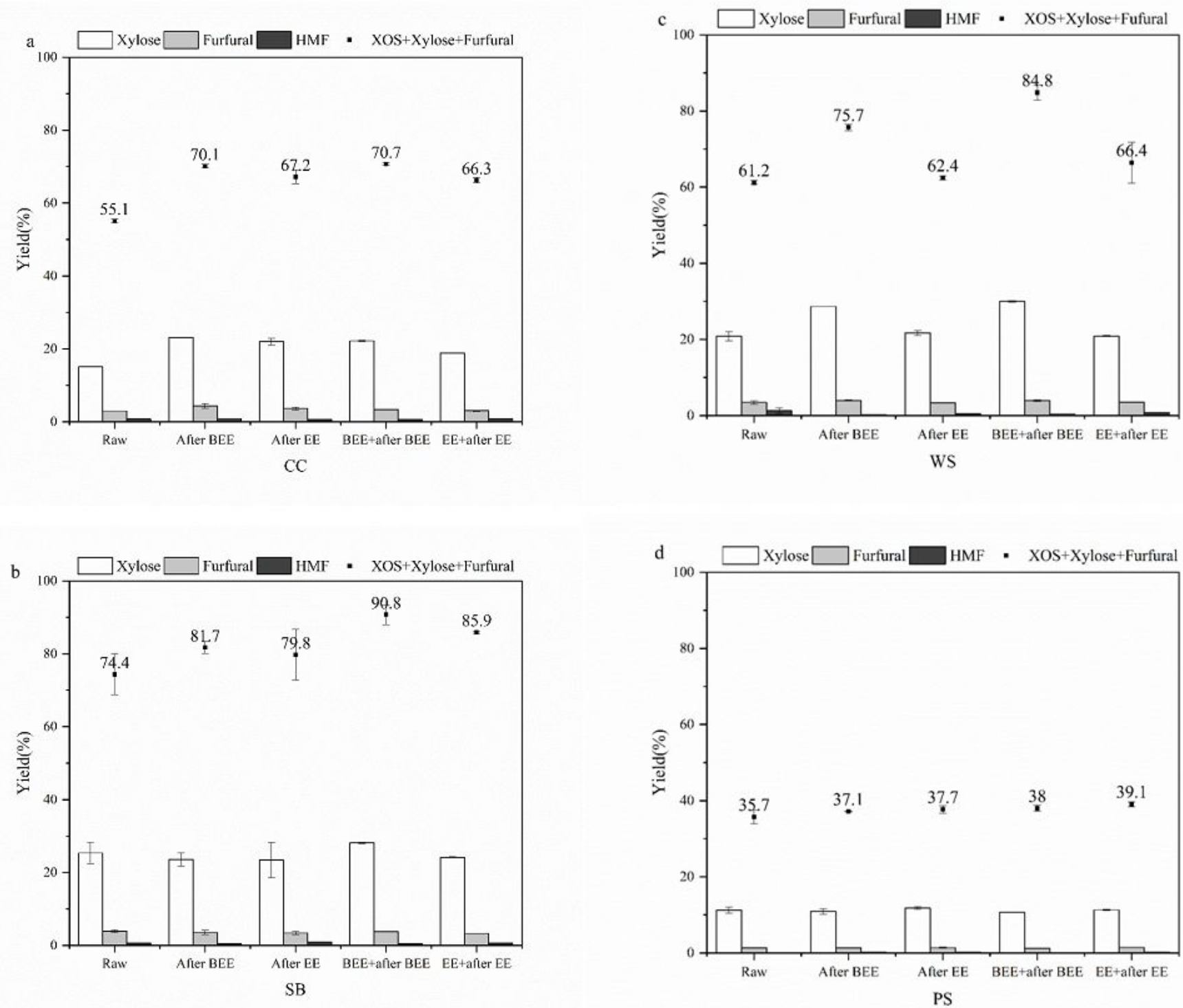

Figure 2

Degradation mechanism of by-products during the catalysis of various agricultural residues with acetic acid. (a) Corncob; (b) Sugarcane bagasse; (c) Wheat straw; (d) poplar sawdust 

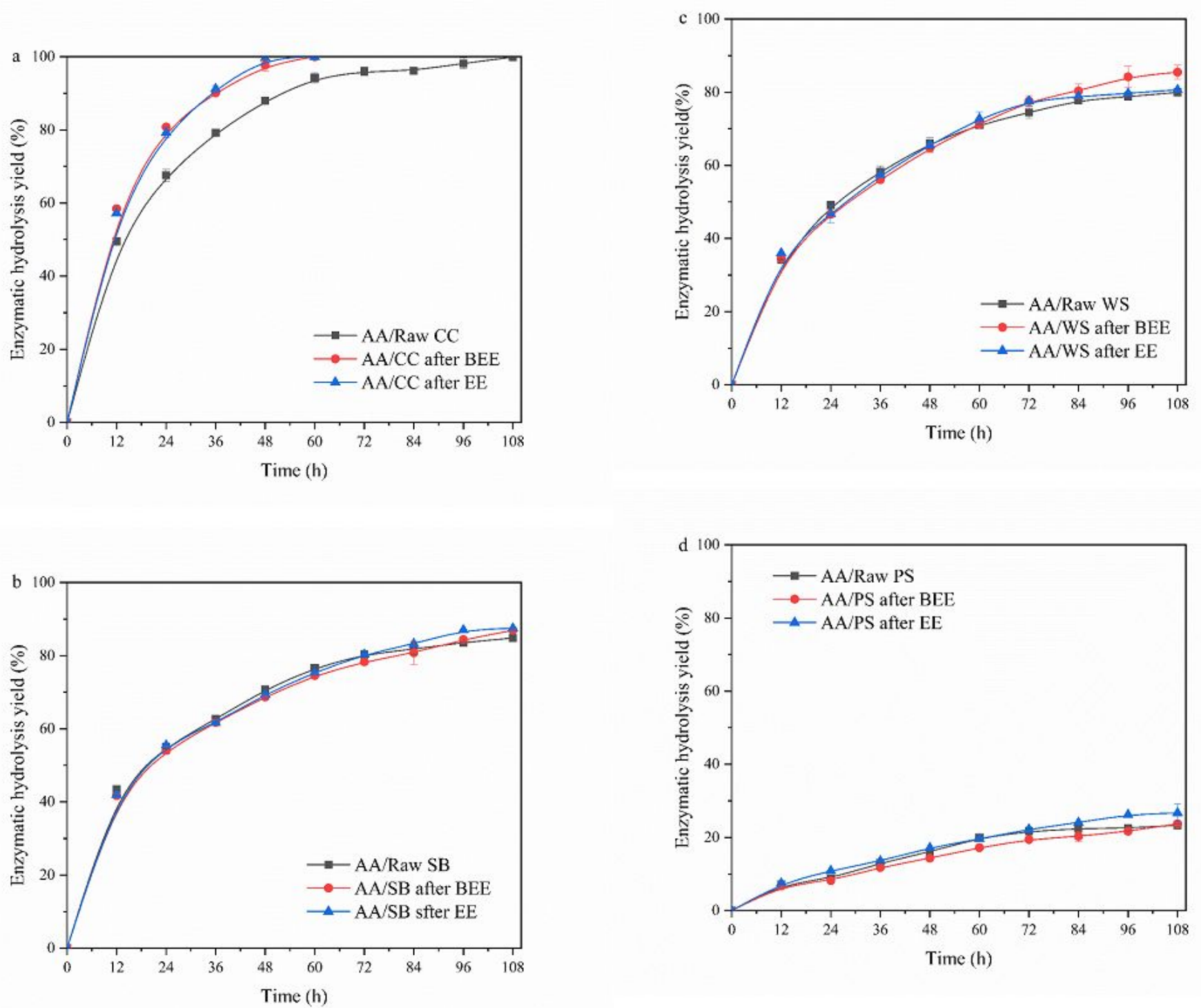

Figure 3

Enzymatic hydrolysis of solid residues treated with acetic acid from various agricultural residues before and after extraction. (a) Corncob; (b) Sugarcane bagasse; (c) Wheat straw; (d) poplar sawdust 


\section{Figure 4}

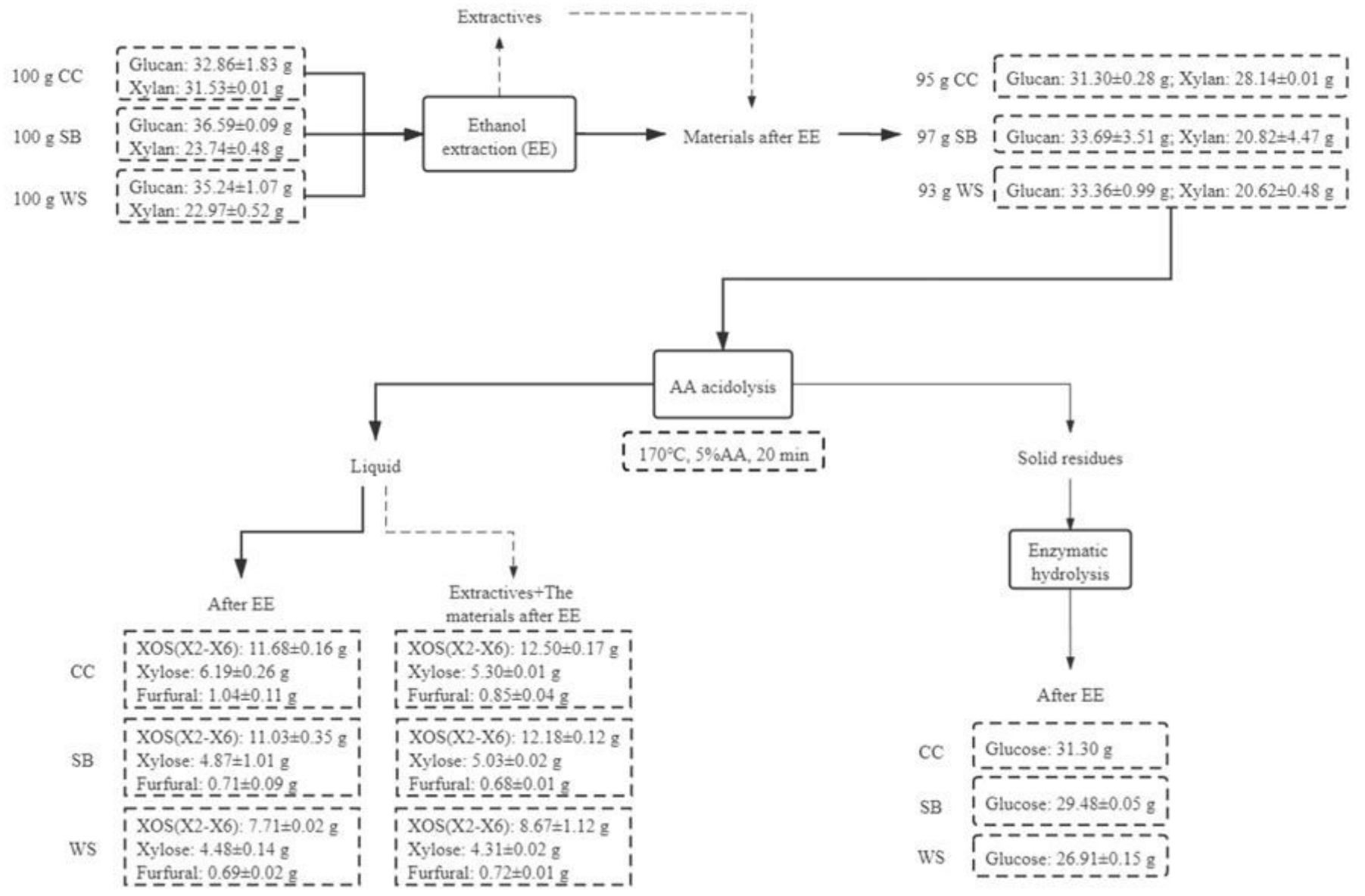

Figure 4

Comparison of the mass balance of the products of acetic acid acidolysis and enzymatic hydrolysis from the agricultural residues after $\mathrm{EE}$ 